\title{
Article \\ Thermo-Chemical Conversion of Microwave Selectively Pre-Treated Biomass Blends
}

\author{
Linards Goldšteins ${ }^{1, *}$, Māris Gunārs Dzenis ${ }^{1}$, Raimonds Valdmanis ${ }^{1}$, Maija Zaḳe ${ }^{1}$ and Alexandr Arshanitsa ${ }^{2}$ \\ 1 Institute of Physics, University of Latvia, Miera str. 32, LV-2169 Salaspils, Latvia; \\ maris_gunars.dzenis@lu.lv (M.G.D.); raimonds.valdmanis@lu.lv (R.V.); Maija.Zake@lu.lv (M.Z.) \\ 2 SIA “EkoKompozit”, Skolas str. 13-7, LV-2121 Salaspils, Latvia; arshanica@edi.lv \\ * Correspondence: Linards.Goldsteins@lu.lv; Tel.: +371-29-892-661
}

check for updates

Citation: Goldšteins, L.; Dzenis, M.G.; Valdmanis, R.; Zake, M.; Arshanitsa, A. Thermo-Chemical Conversion of Microwave Selectively Pre-Treated Biomass Blends. Energies 2022, 15, 755. https://doi.org/ $10.3390 /$ en15030755

\section{Academic Editor: Dino Musmarra}

Received: 22 October 2021

Accepted: 17 January 2022

Published: 20 January 2022

Publisher's Note: MDPI stays neutral with regard to jurisdictional claims in published maps and institutional affiliations.

Copyright: (C) 2022 by the authors. Licensee MDPI, Basel, Switzerland. This article is an open access article distributed under the terms and conditions of the Creative Commons Attribution (CC BY) license (https:// creativecommons.org/licenses/by/ $4.0 /)$.
Abstract: Possibilities of more efficient use of regional lignocellulosic resources (wood, wheat straw, peat) of different origin for an environmentally friendly energy production using selectively MW pre-treated blends of commercial wood or wheat straw pellets with raw peat pellets are studied. A hypothesis is proposed and tested that selective MW pre-treatment of wood or wheat straw pellets at the frequency $2.45 \mathrm{GHz}$ and blending of MW pre-treated pellets with raw peat pellets can be used to enhance and control the thermo-chemical conversion of biomass blends. To test this hypothesis, a combined experimental study and mathematical modelling of the processes were performed. The thermo-chemical conversion of selectively activated blends was experimentally studied using a batch-size pilot device, which consists of a biomass gasifier and a combustor. To evaluate the effect of selective MW pre-treatment of biomass pellets on the thermo-chemical conversion of pre-treated blends, measurements of the kinetics of weight loss, yield of combustible volatiles, flame temperature, heat output of the device, and composition of emissions were made at different MW pre-treatment regimes of wheat straw and wood pellets and different mass fractions of pre-treated pellets in biomass blends. The developed novel 2D numerical model of thermo-chemical conversion of MW pre-treated straw confirmed that the pre-treatment of wheat straw pellets increases the generated heat and significantly affects the temperature distribution in the flame/bed zones. It was confirmed that MW pre-treatment leads to a faster thermal decomposition of biomass pellets, synergistically activating the non-treated parts of blends. The overall improved yield of combustible volatiles and their complete combustion provide a surplus of heat production by limiting the formation of GHG emissions, which allows promoting MW pre-treated biomass of different origin as efficient regional bioenergy resources for energy production.

Keywords: wheat straw; softwood; peat; pellet blends; microwave pre-treatment; thermal decomposition; combustion; heat production

\section{Introduction}

To reduce still growing global warming, the 2030 Climate Target Plan of the EU Commission proposes to raise the EU's ambition on reducing greenhouse gas (GHG) emissions from $40 \%$ to at least 55\% below 1990 levels by 2030 to become climate-neutral by 2050 [1]. To ensure such a reduction in GHG emissions, it is necessary to limit the use of fossil energy sources (coal, natural gas, etc.) for energy production by gradually replacing them with renewable energy sources. The use of lignocellulosic biomass from different feedstock (agriculture, wood residues, peat) provides a more stable and sustainable energy production than other renewable sources such as solar, wind, or hydro energy, all significantly affected by changes in weather conditions.

Bioenergy is the largest energy source, preceded by oil, coal, and natural gas [2]. Unlike solar and wind energy, all used predominantly for electricity production, plant biomass is mainly used to produce biofuels available for both heat and power generation 
and can be stored in solid, liquid, and gaseous states [3]. This implies that biomass is a very prospective renewable resource to replace fossil fuels thus reducing GHG during energy production.

Wood pellets are currently the most widely used fuel for local heat production which are characterized by a relatively high calorific value (up to $21 \mathrm{MJ} / \mathrm{kg}$ on dry matter) and a low ash content $(<0.5 \%)$ in pellets. Due to the intensive use of wood pellets in heat production, their deficit is growing, and heat producers increasingly use biofuels of different origin (wood, peat, straw). However, biomass of different origin, for example, wood waste, agriculture residues (straw) and partially bio-decomposed plant biomass (peat), has a dissimilar structure, bulk density, and widely ranging (varying) biomass elemental and chemical composition. These factors determine the heating value of biomass which is significantly lower compared to that of fossil coal, which limits its applicability for energy production [4]. Therefore, to overcome this limitation and to expand biomass use in industrial and other sectors, a variety of conversion technologies have been developed, including physical, biological, chemical, and thermo chemical methods [5].

Drying and grinding followed by pelletizing are the most widely used physical methods for improving fuel properties of raw biomass. For a predictable energy production from plant biomass, the biomass feedstock should be shaped as pellets or briquettes to ensure controllable density, structure, elemental, and chemical composition and controllable combustion characteristics of biofuel. Biomass pelletizing results in improving the homogeneity and composition of biomass fuels and decreases the moisture content. Pelletizing also enhances the energy density of biomass by increasing its bulk density, with no influence on the content and structure of the main cell wall components, e.g., cellulose, lignin, hemicellulose, and on the calorific value of biomass pellets. To additionally control and improve the main characteristics of the lignocellulosic biomass feedstock, biomass torrefaction can be used providing mild pyrolysis at $200-350{ }^{\circ} \mathrm{C}$ which converts the biomass to a high-quality solid fuel with the improved energy density, homogeneity, and grindability [6], increased calorific values and hydrophobicity of plant biomass [7-9].

During the biomass pre-treatment in inert media at $250-350{ }^{\circ} \mathrm{C}$, the thermal chemical transformation of the lignocellulosic matrix takes place, accompanied by partial devolatilization of biomass. The released volatiles consist mainly of low molecular organic compounds enriched with oxygen formed as a result of biomass constituent's depolymerization/degradation (predominantly hemicellulose). Besides, cellulose dehydration and partial condensation of lignin result in the release of chemically bonded water $[8,10]$.

The energy yield during biomass torrefaction is greater than the mass yield, producing a material with an increased heating value, close to that of coal. The modification of biomass characteristics during torrefaction enhances the combustion performance of treated biomass in regimes of single combustion, co-combustion, and co-firing, particularly in boilers for energy production and for pyrolysis and gasification applications and also provides its better storage $[6,7]$.

At present, the torrefaction of plant biomass is realized using traditional convective/conductive heating of plant chips. Until 2016, about 5 enterprises in the world manufactured torrified fuel biomass on a industrial scale $(\geq 2 \mathrm{t} / \mathrm{h})$ and about 20 pilot plants manufactured about $0.05-2 \mathrm{t} / \mathrm{h}$, with the total annual product output about 386,000 $\mathrm{t}$ [11] The market of torrefied fuel in Europe is constantly expanding, and in 2020 a new plant of torrefied pellet with a capacity of $160,000 \mathrm{t} / \mathrm{y}$ was launched (put into operation) in Estonia [12]. For torrefied pellets, it was shown that the global greenhouse emission (GHG) per GJ of heat was by 30-50\% lower in comparison with that of conventional pellets [13]. Net benefit, expressed in USD/GJ, taking into account the cost of raw material, the charge for production and shipping was 30\% higher when using torrefied pellets compared with conventional pellets. This is clear evidence that pellets from torrefied biomass are a step forward to substitute fossil carbon with renewable carbon for heat and energy production.

The process of torrefaction is endothermic which needs heat energy supply for the activation and control of biomass devolatilization. Therefore, the search for innovative 
heating methods to decrease energy consumption and to accelerate this process is an important task. Most of the recent studies on biomass torrefaction are related to conventional heating using electric or gas heating. However, other studies conclude that the microwave (MW) pre-treatment of lignocellulosic biomass at the $2.45 \mathrm{GHz}$ frequency offers several advantages over conventional heating and significantly influences the yield and characteristics of the products [14,15], determining higher gas and solid yields than the conventional pre-treatment technology and a higher heating value of pre-treated biomass. Therefore, using MW irradiation as an alternative source of energy instead of conventional heating for biomass thermal conversion is in active development [16].

In the case of MW pre-treatment, the direction of the temperature gradient changes and the volumetric heating of biomass is realized at the temperature gradient directed from the inside out. It is the reason of the accelerated selective and hence less energy consumptive process of biomass heating, despite its low thermo conductivity. The process of different biomass pellets MW assisted torrefaction in terms of the fuel characteristic, biomass component transformation, mass and energy balances, and energy consumption has been already described $[17,18]$. Using the PY-GC/MS method, it was shown that at a temperature of $200-300^{\circ} \mathrm{C}$ the transformation of the softwood structure is more significant if compared with that of the samples after convective heating. As evidence of this observation, a higher condensation of lignin and a higher crystallinity of cellulose in the MW treated biomass samples were observed. The MW treatment of wheat straw also results in the development of $\mathrm{C}-\mathrm{C}$ links formed between the phenylpropane units of lignin and in the coupling of lignin with the products of carbohydrate formation via C-C bonds [19]. The results presented testify that the MW assisted pre-treatment is a fast and effective method of upgrading the fuel properties of plant biomass by combining depolymerization/destruction and condensation reactions which proceed in the lignocellulosic matrix of different biomass samples [20].

Improving the characteristics of biomass feedstock of different origin during pelletization and pre-treatment enhances their applicability for energy production with improved energy quality. This makes possible the replacement of the widely used wood pellets by biomass pellets of different origin (wheat straw, peat, etc.), thus providing a more intensive use of available local bioenergy resources and improving energy production. As a result, heat producers can increasingly use biomass blends of different origin (wood, peat, straw, coal) in different proportions, which currently is a common practice in the fixed bed installations [21]. Using fuel blends of different origin, such as biomass and coal, for heat production allows to conclude that their thermo-chemical conversion and combustion characteristics are highly influenced by the thermal and chemical interactions of their components, indicating the occurrence of synergetic effects on the thermal decomposition of biomass blends with non-additive interactions between the components during their thermal decomposition [22-26].

The development of synergetic effects depends on a number of factors, such as the blending ratio of components, temperature, type of fuels, and their elemental composition [22] when varying the reactivity and activation energy of fuel blends [23,24]. Besides, the synergetic effects at thermal decomposition of biomass blends are influenced by the chemical composition of lignocellulosic biomass. In accordance with the research result of [25], the thermal decomposition of cellulose shows positive synergetic effects on the thermo-chemical conversion of biomass, whereas the thermal decomposition of hemicellulose and lignin can result in positive or negative synergistic effects which depend on the composition and temperature of fuel blends.

Therefore, if biomass blends consist of components of dissimilar elemental and chemical composition, the synergism between the components influences the thermal behaviour of the blends $[24,26]$, which is confirmed by a modelling study on the co-pyrolysis of biomass and plastic wastes [27]. This suggests that the thermal behaviour of biomass blends can be controlled by providing selective MW pre-treatment of the blend components, which results in partial thermal destruction of the main constituents of lignocellulosic 
biomass [28], promoting changes in their structure, in chemical and elemental composition responsible for the variations of the rate of thermal decomposition, of the yield of volatiles, and formation of char [29]. Moreover, an increase of the heating values, specific surface area, and reactivity of MW pre-treated biomass particles [14,15] affects the kinetics of the thermo-chemical conversion of selectively activated biomass blends which are composed of MW pre-treated and raw biomass pellets of different origin [30]. The deviation from linear approximation, assuming the additivity of the weight loss rates of selectively activated blend components, confirms that the MW pre-treatment of pellets activates the synergetic interactions between the pre-treated and raw biomass pellets. This supports the enhanced yield and burnout of volatiles, thus improving the composition of emissions, decreasing the mass fraction of polluting $\mathrm{NO}$ emissions, and increasing the overall combustion efficiency and heat output [30,31].

The results of the presented study are used to assess the optimal MW pre-treatment regimes of lignocellulosic biomass pellets of different origin (wheat straw, wood) and the optimal composition of the pre-treated and raw pellet blends to provide their most effective thermo-chemical conversion with the highest yield of combustible volatiles, increased reactivity of blends, and increased amount of produced heat energy. The thermo-chemical conversion of biomass pellets (wheat straw) are mathematically modelled, considering the effects of MW pre-treatment on the produced heat energy and composition of emissions.

\section{Experimental Equipment and Methods}

The thermo-chemical conversion of selectively pre-treated blends $\left(\right.$ straw $^{*}+$ peat, wood $^{*}+$ peat) of biomass pellets of different origin was experimentally studied using a pilot-scale device with an average heat output up to $5 \mathrm{~kW}$. The device consists of a biomass gasifier and three water-cooled sections of the combustor reactor of average diameter 88 and $1200 \mathrm{~mm}$ length, which was connected to the outlet of the gasifier [29]. The gasifier was filled from the top of the device with a blend of MW pre-treated and raw biomass pellets. The average diameter of the pellets was $8 \mathrm{~mm}$, and the average length was $10-35 \mathrm{~mm}$. The total average weight of blends was $400-540 \mathrm{~g}$. To initiate thermal decomposition/gasification of biomass blends, an additional heat by a propane flame flow with the average heat power $0.7 \mathrm{~kW}$ was injected at the top of the biomass blend and it was terminated upon ignition of volatiles. The primary air was supplied below the fuel bed to support the gasification of the biomass blend. The average primary air-to-fuel supply rate was $40 \mathrm{~L} / \mathrm{min}$. The average air-to-fuel supply ratio during the gasification of blends was $\alpha \approx 0.4-0.5$. The secondary swirling air was introduced at the inlet of the combustor through the tangential nozzles to provide mixing of the air swirl with the axial flow of combustible volatiles $\left(\mathrm{CO}, \mathrm{H}_{2}, \mathrm{C}_{\mathrm{x}} \mathrm{H}_{\mathrm{y}}\right)$ and to support their ignition and combustion. The average secondary air supply rate was $60 \mathrm{~L} / \mathrm{min}$, determining the air-to-fuel supply ratio $\alpha \approx 1-1.5$.

\subsection{Weight Loss Measurements of Blends}

With the given pilot device configuration, the thermal decomposition of biomass proceeded with the formation of a hot biomass layer above the biomass pellets with the average temperature $800-1000 \mathrm{~K}$, supporting the gasification of biomass pellets and their blends. The gasification of blends resulted in their weight loss. The average weight loss of blends was evaluated by preliminary measurements of their specific mass density ( $\rho$, $\left.\mathrm{g} / \mathrm{cm}^{3}\right)$ and by continuous measurements of the height variation of the biomass layer $(\mathrm{dL} / \mathrm{dt}, \mathrm{cm} / \mathrm{s})$ during the gasification of the blends. With the unchanging specific mass density of the blends and cross-section of the gasifier $\left(\mathrm{S}, \mathrm{cm}^{2}\right), \mathrm{dm} / \mathrm{dt}(\mathrm{g} / \mathrm{s})$ can be expressed as a linear function of the variation in height of biomass blends $\left(\mathrm{dm} / \mathrm{dt}=\mathrm{dL} / \mathrm{dt}^{*}\left(\rho^{*} \mathrm{~S}\right)\right.$. Variations in the height of the biomass layer during the gasification of biomass blends were continuously measured using a sliding ceramic rod of $6 \mathrm{~mm}$ in diameter, resting on the surface of the biomass layer. A rod-mounted pointer allows to control the time-dependent variations of the biomass height with an accuracy of $\pm 1 \%$. Preliminary measurements 
of the biomass volume density of the blends were made to estimate the weight loss rate $\mathrm{dm} / \mathrm{dt} \mathrm{gs}^{-1}$ with an accuracy of $\pm 2 \%$.

\subsection{Measurements of the Yield of Volatile Compounds}

Thermal decomposition of biomass blends during their gasification produces an axial downstream flow of combustible volatiles $\left(\mathrm{CO}, \mathrm{H}_{2}, \mathrm{C}_{\mathrm{x}} \mathrm{H}_{\mathrm{y}}, \mathrm{CO}_{2}\right)$, entering the combustor. The composition of volatiles at the inlet of the combustor was measured by a gas sampling probe. The gas sampling probe was inserted into the axial flow of volatiles through the orifice at the outlet of the gasifier providing gas sampling and testing. The gas samples were analysed using a gas analyser Testo 350 .

\subsection{Measurements of Combustion Characteristics}

Measurements of combustion characteristics include local measurements of the flame temperature, produced heat and composition of emissions. $\mathrm{Pt} / \mathrm{Pt} / \mathrm{Rh}$ thermocouples were used for local online measurements of the flame temperature with an accuracy of $\pm 5 \%$ providing data online registration by a Pico logger. A thermocouple was inserted in the flame reaction zone at the distance $\mathrm{L}=280 \mathrm{~mm}$ from the secondary air supply nozzles through the orifice designed for diagnostic tools.

The heat output from the device was estimated from the data of continuous calorimetric measurements of the cooling water flow temperature at the inlet and outlet of each section with the fixed cooling water mass flow, which was estimated from initial measurements of the cooling water supply for each section with the accuracy $\pm 2.5 \%$. The inlet and outlet temperatures of the cooling water flow were measured with the accuracy $\pm 1 \%$ by thermo sensors AD 560, along with online data recording by the Data Translation DT9805 data acquisition module and Quick DAQ program.

To provide control of the effects of selective MW pre-treatment of pellets on the thermo-chemical conversion of blends, the composition of emissions $\left(\mathrm{CO}_{2}, \mathrm{CO}, \mathrm{NO}\right)$, their temperature $(\mathrm{T})$, the combustion efficiency, and the air excess ratio $(\alpha)$ were measured using a gas sampling probe and a gas analyzer Testo 350 . in [29].

The methodology of the measurements of the combustion characteristics is described

\subsection{Methodology of Biomass Pre-Treatment}

MW pre-treatment of biomass was provided as a two-stage process of biomass heating which combines convective and MW heating of pellets in the argon atmosphere [17]. Commercial softwood, wheat straw, and peat pellets with the moisture contents $7.1 \%$, $10.2 \%$, and $8.9 \%$, correspondingly, were used as an investigation object. Biomass pellets of average mass load $300 \mathrm{~g}$ were subjected to preliminary convective heating up to a temperature of $350 \mathrm{~K}$, which was followed by unsteady microwave heating in the MW resonator and by isothermal MW heating of the pellets at selected temperatures $(\mathrm{T}=473 \mathrm{~K}$ and $\mathrm{T}=548 \mathrm{~K}$ ) for $20 \mathrm{~min}$. The effect of MW pre-treatment on the weight loss of the pellets and on the yields of solid and condensable fractions was controlled by weighing the raw and pre-treated samples. The pre-treated wheat straw or pre-treated wood pellets in different proportions were mixed with raw peat pellets to produce activated biomass blends. The mass fraction of the pre-treated pellets in the blends varied from $15 \%$ to $60 \%$, which allowed us to estimate the effect of variations in the blend composition and pre-treatment temperature on the thermal decomposition of the activated blends as well as on the combustion characteristics and composition of emissions.

\section{Results}

\subsection{Thermal Decomposition of Selectively Activated Biomass Blends}

To estimate the effect of MW pre-treatment of wood and wheat straw pellets on the thermo-chemical conversion of their blends with raw peat pellets, the MW-induced variations of the main characteristics of the blend components and pellets' structure were 
preliminary estimated and considered [30,31]. Wood, wheat straw, and peat have different elemental, chemical compositions, surface area, porosity, and contents of volatile matter in raw biomass. A higher content of volatile matter was found in wood (84.1\%) and wheat straw biomass $(74.8 \%)$, whereas the lowest contents of volatiles were found in peat biomass (67.6\%) [32]. It was shown that MW pre-treatment of wood and wheat straw pellets produced a higher heat output as a result of volatiles combustion if compare with that of raw biomass pellets. This can be explained by the influence of several factors, including the elemental and chemical composition of the lignocellulosic matrix of pre-treated biomass and the morphological structure of pellets.

Increasing the surface area, porosity, and reactivity of pellets and the concentration of the active sites [33] enhances the thermo-chemical conversion of pre-treated pellets [30] which depends on the MW pre-treatment temperature. Increasing the temperature of MW pre-treatment above $470 \mathrm{~K}$ correlated with the carbonization of pre-treated pellets, thus increasing the carbon content in the pre-treated pellets, while decreasing the hydrogen and oxygen content. By increasing the pre-treatment temperature of wood biomass, the carbon content can be increased from $50.5 \%$ in raw wood pellets up to $50.7 \%$ at the MW pre-treatment temperature $\mathrm{T}=473 \mathrm{~K}$ and up to $56.2 \%$ at $\mathrm{T}=548 \mathrm{~K}$, which exceeds the carbon content in raw peat pellets $(52.8 \%)$. The MW pre-treatment of wheat straw pellets correlated with the increase of the carbon content from $46.4 \%$ for raw wheat straw pellets up to $47.2 \%$ at the pre-treatment temperature $\mathrm{T}=473 \mathrm{~K}$ and up to $52.4 \%$ at $\mathrm{T}=548 \mathrm{~K}$, which is slightly less than the carbon content in raw peat pellets (52.8\%). As a result of the elemental composition variations during the pre-treatment of biomass pellets, the high heating value (HHV) of raw wood pellets increased from 19.9 to $22.2 \mathrm{MJ} / \mathrm{kg}$ at the pre-treatment temperature $\mathrm{T}=473 \mathrm{~K}$ and to $22.63 \mathrm{MJ} / \mathrm{kg}$ at $\mathrm{T}=548 \mathrm{~K}$, thus exceeding the heating value of raw peat pellets $20.9 \mathrm{MJ} / \mathrm{kg}$. For straw pellets, the HHV during MW pre-treatment increased from $18.4 \mathrm{MJ} / \mathrm{kg}$ for raw pellets to $18.7 \mathrm{MJ} / \mathrm{kg}$ at $\mathrm{T}=473 \mathrm{~K}$ and to $20.8 \mathrm{MJ} / \mathrm{kg}$ at T $=548 \mathrm{~K}$. Besides, the data of the TG/DTG analysis allowed us to conclude that the enhanced yield of volatiles during MW pre-treatment of pellets and their carbonization results in a decrease of the relative heat output at the combustion stage of volatiles, whereas the heat output increases at the char conversion stage for pre-treated pellets [34]. The highest decrease of the heat output during the combustion of volatiles, if compared to that of char conversion, was observed for the pre-treated wheat straw pellets which had the highest weight loss of volatiles during MW pre-treatment of pellets along with the highest increase in reactivity of the pre-treated pellets $[29,30]$.

The MW-induced variations of the pellets' structure, reactivity, elemental composition, and heating values influenced the thermal decomposition of the selectively activated blends which were produced by mixing pre-treated wood or wheat straw with raw peat pellets, thus varying the kinetics and the average values of the weight loss rates of the selectively activated biomass blends (Figure 1a-f). Comparing the results of the kinetic study on the weight loss rates of biomass blends, it was observed that blending of raw peat with pre-treated straw $\left(\right.$ straw $\left.^{*}\right)$ or wood $\left(\operatorname{wood}^{*}\right)$ pellets caused a faster thermal decomposition of the blends if compared with raw peat, promoting a faster rise of the weight loss rates up to their peak values. The peak values depended on the mass fraction of pre-treated pellets in the blends and on the temperature of MW pre-treatment (Figure 1a-d). 


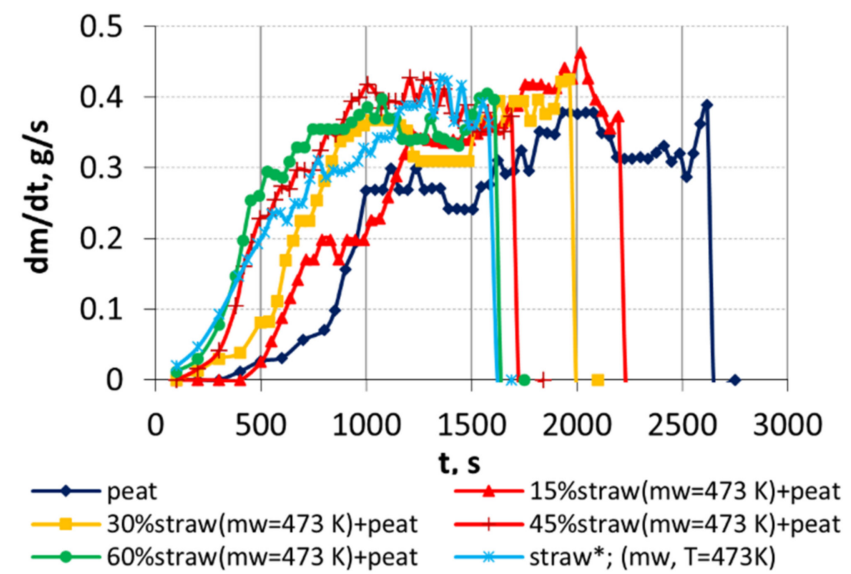

(a)

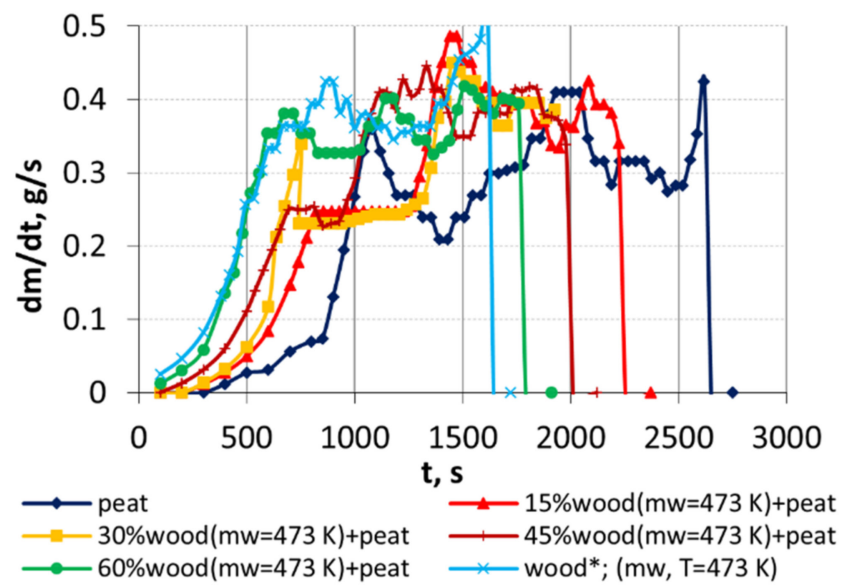

(c)

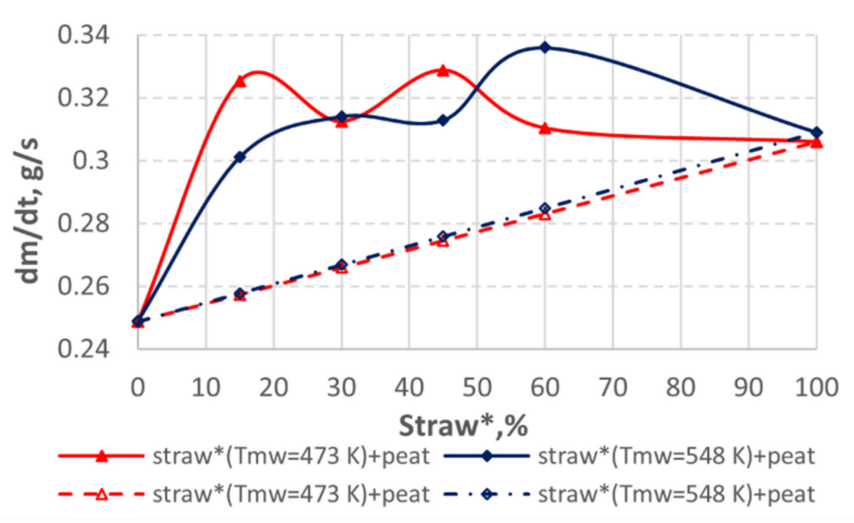

(e)

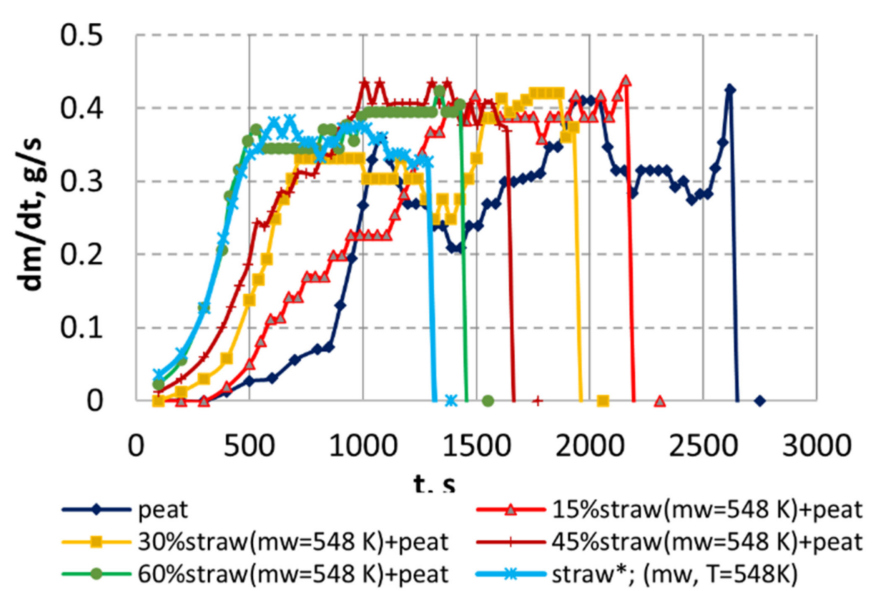

(b)

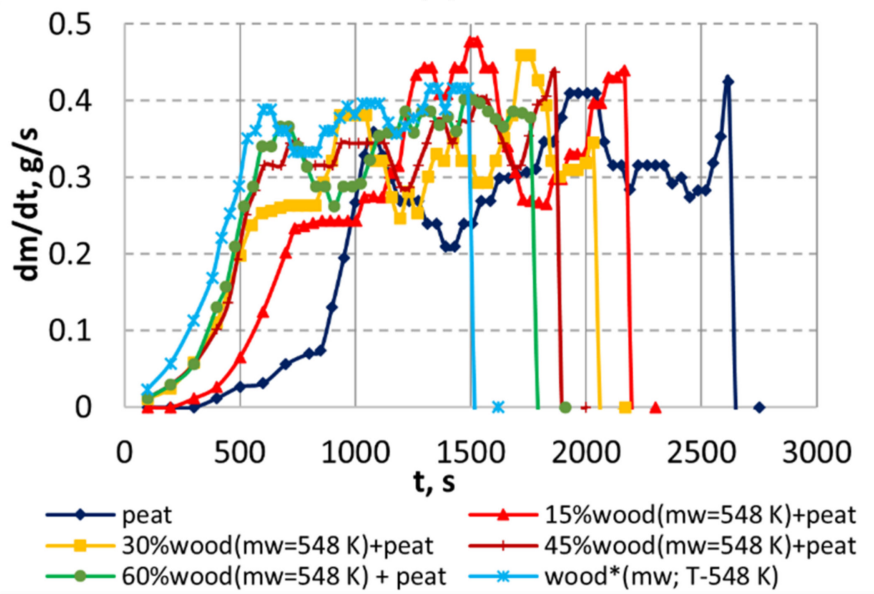

(d)

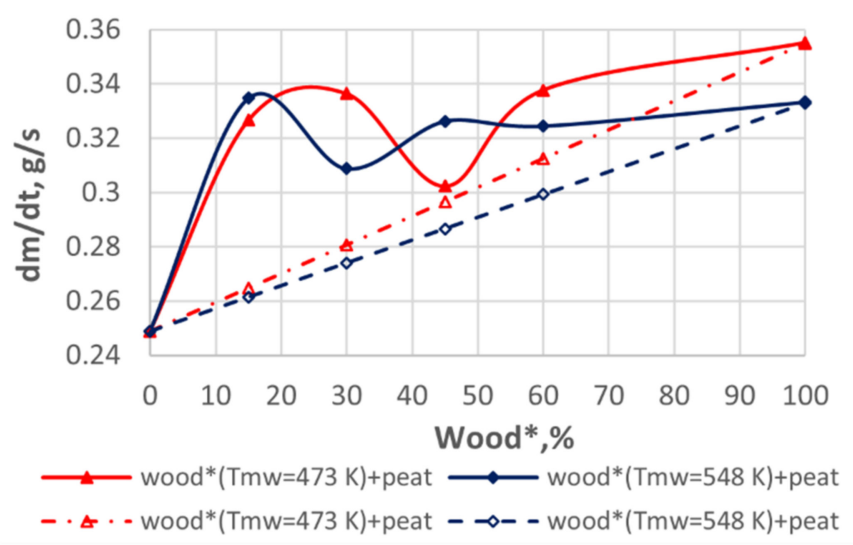

(f)

Figure 1. Effect of changes (variations) in pre-treatment temperature and composition of selectively pre-treated wheat $\operatorname{straw}^{*}(\mathbf{a}, \mathbf{b}, \mathbf{e})$ and $\operatorname{wood}^{*}(\mathbf{c}, \mathbf{d}, \mathbf{f})$ blends with raw peat pellets on the kinetics $(\mathbf{a}-\mathbf{d})$ and average values $(\mathbf{e}, \mathbf{f})$ of the weight loss rates of biomass blends, continuous curve experimental data, dashed line linear interpolation.

The kinetic study of the thermal decomposition of selectively activated biomass blends suggests that there exists a synergetic interaction between the intermediate products of thermal oxidative conversion of pre-treated pellets of wheat straw, wood, and raw peat pellets. When the addition of MW pre-treated pellets was increased, the rate of the thermal decomposition of blends increased in a non-linear manner compared with that of the untreated components of blends. This suggestion was confirmed by measuring the average 
values of the weight loss rates when varying the mass fraction of the pre-treated pellets. Results of these measurements indicate a deviation of the weight loss rates of the blend from linearity, which can be obtained assuming the additivity of the weight loss rates of the blend components (1) (Figure 1e,f).

$$
\frac{d m}{d t}=C_{*}\left(\frac{d m}{d t}\right)_{*}+C_{0}\left(\frac{d m}{d t}\right)_{0}
$$

where $\frac{d m}{d t}, \mathrm{~g} / \mathrm{s}$ is the weight loss rate of the blend, $\left(\frac{d m}{d t}\right)_{*}, \mathrm{~g} / \mathrm{s}$ is the weight loss rate of MW pre-treated wheat straw or wood pellets, $\left(\frac{d m}{d t}\right)_{0}, \mathrm{~g} / \mathrm{s}$ is the weight loss rate of raw peat pellets, $C_{*}$ is the mass fraction of pre-treated pellets, and $C_{0}$ is the mass fraction of raw pellets in the blend.

As follows from Figure 1e,f, by increasing the mass fraction of MW pre-treated pellets (straw, wood) in the blend with raw peat pellets, a pronounced increase in the weight loss rate of the blends during their thermal decomposition was observed even at a relatively low mass fraction of the pre-treated pellets (wood, straw) in the biomass blend (15-30\%). The weight loss rate increased by $\approx 35 \%$ when the blends were added with wood pellets with a higher heating value and a higher content of volatile matter in biomass than that for wheat straw. A lower increase of the weight loss rate with additives of wheat straw $(\approx 26.6-30 \%)$ was observed. Moreover, the synergetic effect on the weight loss rate of the blends gradually decreased, which increased the mass fraction of the pre-treated additives in the blend by more than $45-60 \%$.

The variations of the weight loss rate during thermal decomposition of selectively activated biomass blends correlate with variations in the yield of volatiles. Just as with the kinetics of the thermal decomposition of biomass pellets (wood, wheat straw, peat) of different origins, the thermal decomposition of selectively activated biomass blends starts with the primary stage of endothermic drying of the blend components. For blends of MW pre-treated wheat straw or wood pellets with raw peat pellets, during this stage endothermic drying of raw peat pellets is a dominant process. These pellets have a higher moisture content in raw biomass $(8.9 \%)$ compared to the moisture content in the pretreated wood and wheat straw pellets (1-1.6\% on the average). The primary stage of biomass blend endothermic drying was followed by the thermal decomposition of the main blend components.

The TG/DTA analysis of the oven-dried biomass testified that there are endothermic and exothermic regions responsible for the thermal oxidative decomposition of the main biomass components. The area of the endothermic region on the DTA curve was proportional to the energy required for the release of volatiles to advance the exothermic effect of their combustion. In this region, the energy balance was shifted towards input energy, which changed to output energy when the onset temperature was reached, and the exothermic process took place [34].

It was observed that the exothermic process with the MW treated biomass started at lower temperatures with a lower actual weight loss, compared to that of raw biomass. It was determined that, in comparison with the MW treated biomass, a significant amount of volatiles was released during thermal oxidative conversion of raw biomass. This resulted in a less efficient utilization of the potential of raw biomass instead of torrefied biomass [34]. The DTA data were confirmed by the results of the combustion experiment.

Because MW pre-treatment activates the thermal decomposition of pre-treated wood and wheat straw pellets, they decompose faster than raw peat pellets, leading to an elevated yield of volatiles [29]. The thermal decomposition of partly carbonized MW pre-treated pellets is responsible for the enhanced yield of energy enriched volatiles $\mathrm{CO}, \mathrm{H}_{2}, \mathrm{CH}_{4}$ [35] This is attributed to their lower dissolution by non-combustible volatiles, such as organic acids, chemically bonded water, $\mathrm{CO}_{2}$, etc., as these compounds are mostly removed from biomass as a result of MW-assisted pre-treatment. Obviously, the combustible gas-phase volatiles $\left(\mathrm{CO}, \mathrm{H}_{2}, \mathrm{CH}_{4}\right)$, which escape from pre-treated biomass pellets into the porous 
space of the packed bed, interact with moisture and chemically bonded $\mathrm{H}_{2} \mathrm{O}$ which is released from raw peat pellets, with the primary air flow and with the carbonized surface of pellets. All this determines the partial thermo-chemical conversion of volatiles.

The main processes that determine the formation of volatile compounds (2) and their chemical transformations in the packed bed of biomass blends can be summarized considering the development (evolution) of exothermic and endothermic reactions of the thermal decomposition of hemicelluloses, cellulose, and lignin (2) [35], the development of gas-phase reactions of volatiles combustion (3-5), and the development of endothermic and exothermic surface reactions (6-10):

$$
\begin{array}{cc}
\mathrm{C}_{x} \mathrm{H}_{y} \mathrm{O}_{z}+\text { heat } \rightarrow a \mathrm{CO}_{2}+b \mathrm{H}_{2} \mathrm{O}+c \mathrm{CH}_{4}+d \mathrm{CO}+e \mathrm{H}_{2}+\text { char }+ \text { tar } \\
\mathrm{H}_{2}+0.5 \mathrm{O}_{2} \rightarrow \mathrm{H}_{2} \mathrm{O} & \Delta \mathrm{H}=-242 \mathrm{~kJ} / \mathrm{mol} \\
\mathrm{CO}+\mathrm{H}_{2} \mathrm{O} \leftrightarrow \mathrm{CO}_{2}+\mathrm{H}_{2} & \Delta \mathrm{H}=-40.83 \mathrm{~kJ} / \mathrm{mol} \\
\mathrm{CO}+0.5 \mathrm{O}_{2} \rightarrow \mathrm{CO}_{2} & \Delta \mathrm{H}=-283 \mathrm{~kJ} / \mathrm{mol} \\
\mathrm{C}+0.5 \mathrm{O}_{2} \rightarrow \mathrm{CO} & \Delta H=-123.1 \mathrm{~kJ} / \mathrm{mol} \\
\mathrm{C}+\mathrm{O}_{2} \rightarrow \mathrm{CO}_{2} & \Delta H=-393.5 \mathrm{~kJ} / \mathrm{mol} \\
\mathrm{C}+\mathrm{CO}_{2} \rightarrow 2 \mathrm{CO} & \Delta \mathrm{H}=+159.9 \mathrm{~kJ} / \mathrm{mol} \\
\mathrm{C}+\mathrm{H}_{2} \mathrm{O} \leftrightarrow \mathrm{CO}+\mathrm{H}_{2} & \Delta H=+118.5 \mathrm{~kJ} / \mathrm{mol} \\
\mathrm{C}+\mathrm{H}_{2} \rightarrow \mathrm{CH}_{4} & \Delta H=-87.5 \mathrm{~kJ} / \mathrm{mol}
\end{array}
$$

In Figure 2, the release of combustible volatiles $\left(\mathrm{CO}, \mathrm{H}_{2}\right)$ is shown depending on the blend composition. For the blends of pre-treated wheat straw and raw peat pellets with a low mass fraction of pre-treated wheat straw pellets in the blends $(\approx 15-30 \%)$, a dominating decrease in the average yield of combustible volatiles $\left(\mathrm{CO}, \mathrm{H}_{2}\right)$ is pronounced which reaches minimum values (Figure 2a,b), whereas the average weight loss of the blend increases (Figure 1e). This suggests that with the low mass fraction of pre-treated wheat straw pellets in the blend the weight loss of the blend during gasification is influenced by endothermic drying of raw peat pellets, which provides the enhanced release of moisture. At the same time, the thermal decomposition of the blend and the yield of combustible volatiles are both limited by this drying process. The negative effect of endothermic drying of peat on the yield of combustible volatiles is reduced by increasing pre-treatment temperature of wheat straw pellets to $548 \mathrm{~K}$, which activates the thermal decomposition of wheat straw [29] and the mass fraction of pre-treated wheat straw pellets in the blend (Figure 2a).

It should be noted that with the constant primary air supply into the device, the enhanced yield of combustible volatiles $\left(\mathrm{CO}, \mathrm{H}_{2}\right)$ during thermal decomposition of pretreated pellets results in a decrease of the air-to-fuel ratio during gasification of biomass blends. This is a result of the decreased thermo-chemical conversion of combustible volatiles that are released from the pre-treated wheat straw pellets into the porous biomass blend. Consequently, the decrease in the amount of heat released during the gasification of biomass blends is observed, which is responsible for the decrease of the synergetic effect on the weight loss rate (Figure 1e,f).

The decrease of the air-to-fuel ratio was confirmed by the measurements of the air excess ratio above the biomass layer. With the constant primary air supply into the device which increases the pre-treatment temperature of wheat straw pellets to $548 \mathrm{~K}$ and the mass fraction of pre-treated pellets in the blend above $45-60 \%$, the air-to-fuel supply ratio decreased from $\alpha=0.48$ during thermal decomposition of raw peat pellets to about $\alpha=0.41-0.36$ during thermal decomposition of selectively activated wheat straw blends. 


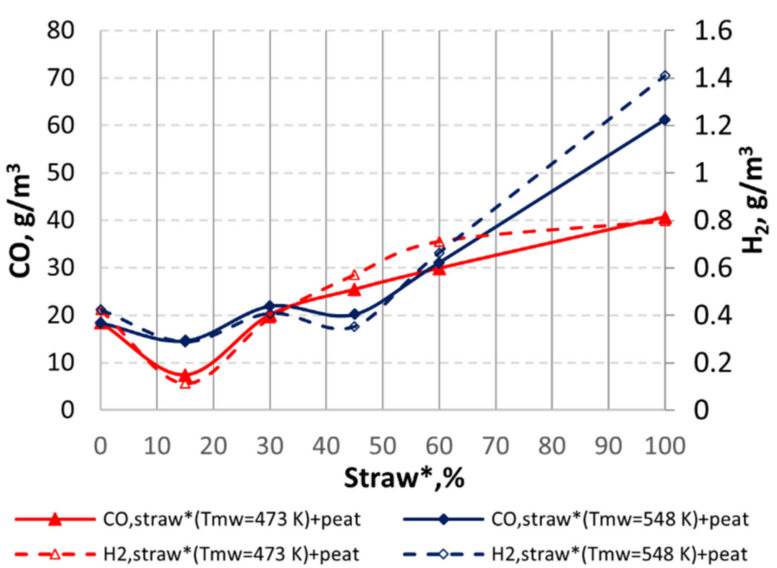

(a)

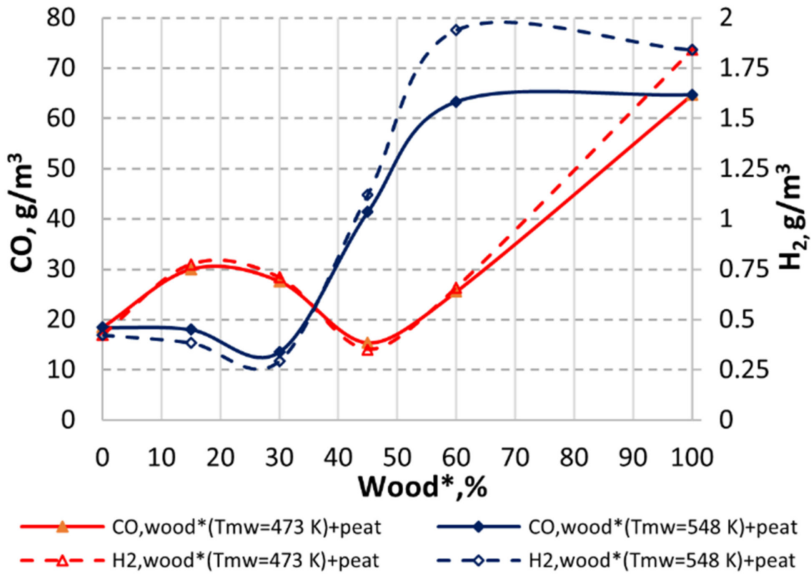

(b)

Figure 2. Effect of changes (variations) in composition and pre-treatment temperature of selectively pre-treated wheat $\operatorname{straw}^{*}(\mathbf{a})$ and $\operatorname{wood}^{*}(\mathbf{b})$ blends with raw peat pellets on the yield of combustible volatiles at the gasifier outlet.

Due to the higher heating value of wood pellets and the higher content of volatiles if compared with that of straw $[4,29]$, the negative effect of endothermic drying of peat on the thermal decomposition of wood blends with raw peat pellets is less pronounced (Figure $2 b$ ). With a low mass fraction of wood pellets in the blend (15-30\%), a slight increase of the yield of volatiles was observed which suggests a synergistic effect of the thermal interaction between the components on the weight loss of the blend. The lower yield of volatiles at the higher MW pre-treatment temperature of wood pellets suggests a loss of volatiles during the pre-treatment of wood pellets. Similar to what was observed for the blends of wheat straw, increasing the pre-treatment temperature of wood pellets and the mass fraction of pre-treated wheat straw in the blends above $30-45 \%$ results in a gradual decrease of the synergetic effect on the weight loss of the blend. Moreover, the decrease of the airto-fuel supply ratio during the gasification of the blend (from $\alpha \approx 0.47$ to $\alpha \approx 0.36-0.41$ on the average) confirms the limited thermo-chemical conversion of volatiles and heat release into the porous biomass blend responsible for the limited thermal interaction of the blend components.

\subsection{Combustion Characteristics of Selectively Activated Biomass Blends}

The kinetic study of the temperature of the flame reaction zone confirmed the synergetic interaction of the components of selectively activated biomass blends. Increasing the mass fraction of MW pre-treated wheat straw or wood pellets in the blends with raw peat pellets results in a faster rise of the flame temperature to the peak value and in a faster transition to the self-sustaining burnout of volatiles. The temperature peak value depends on the mass fraction of MW-pre-treated pellets in the blend and on the pre-treatment temperature of pellets (Figure 3a-d).

The estimation of the influence of the blend composition and pre-treatment on the average values of the flame temperature allows us to conclude that similarly to the observed variations of the weight loss of pellets, increasing the mass fraction of pre-treated pellets in the blends results in an increase of the average flame temperature up to its peak values. The average flame temperature again starts to decrease if the mass fraction of pre-treated pellets in the blends exceeds $45 \%$. This suggests that as observed with the variations of the average values of the weight loss rate of the blends (Figure 1e,f), the development of the flame reaction zone is influenced by the synergetic interaction between the components. This is confirmed by the deviation of the temperature dependence on the mass fraction of pellets in the blend from linearity (Figure $4 a, b$ ). 


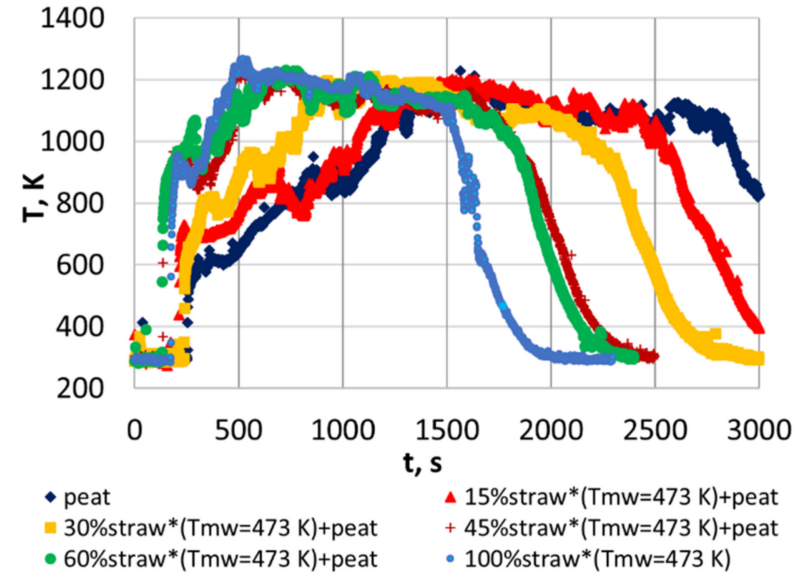

(a)

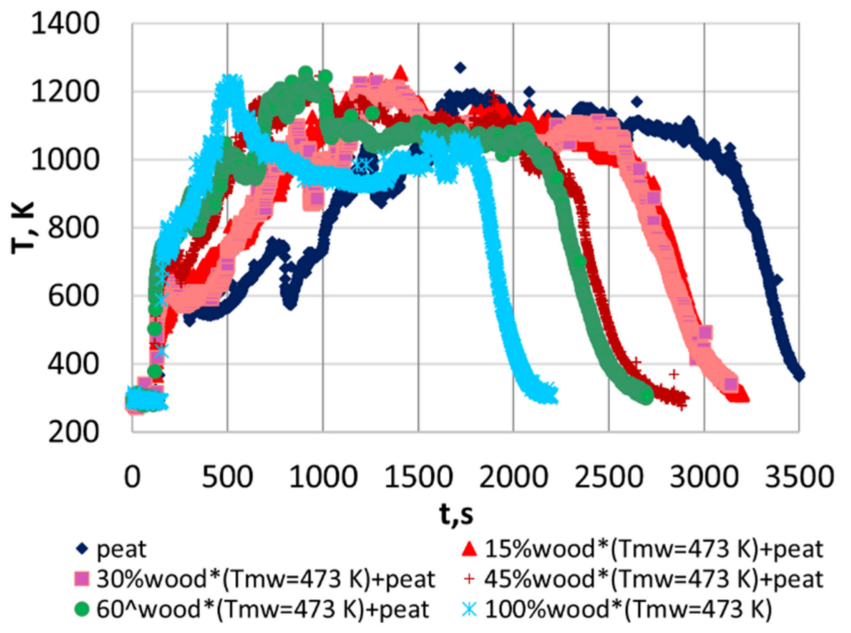

(c)

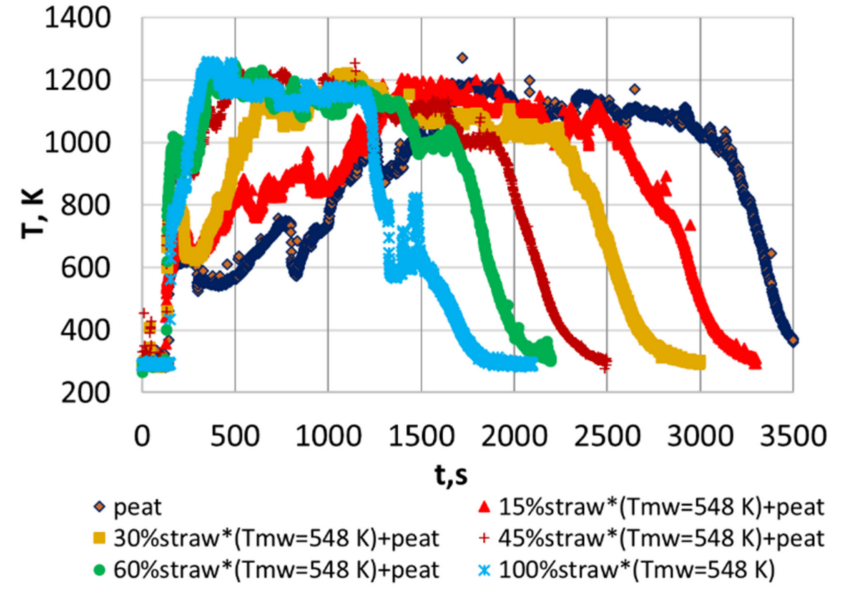

(b)

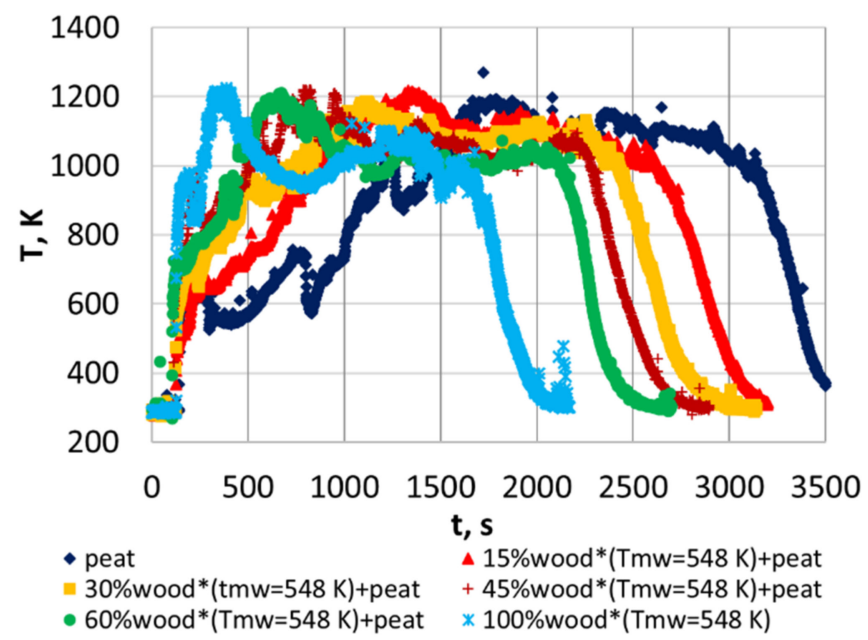

(d)

Figure 3. Effect of changes (variations) in pre-treatment temperature and composition of selectively pre-treated wheat straw $(\mathbf{a}, \mathbf{b})$ and $\operatorname{wood}^{*}(\mathbf{c}, \mathbf{d})$ blends with raw peat pellets on the kinetics of the flame temperature.

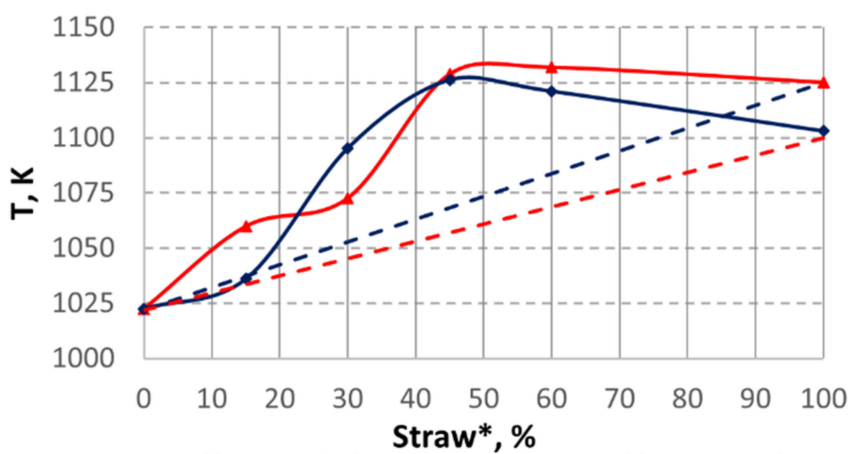

$\longrightarrow$ straw* $(\operatorname{Tmw}=473 \mathrm{~K})+$ peat $\longrightarrow$ straw* $(\operatorname{Tmw}=548 \mathrm{~K})+$ peat

- - - - straw* $(\operatorname{Tmw}=473 \mathrm{~K})+$ peat $\quad$ - - - - straw* $(\operatorname{Tmw}=548 \mathrm{~K})+$ peat

(a)

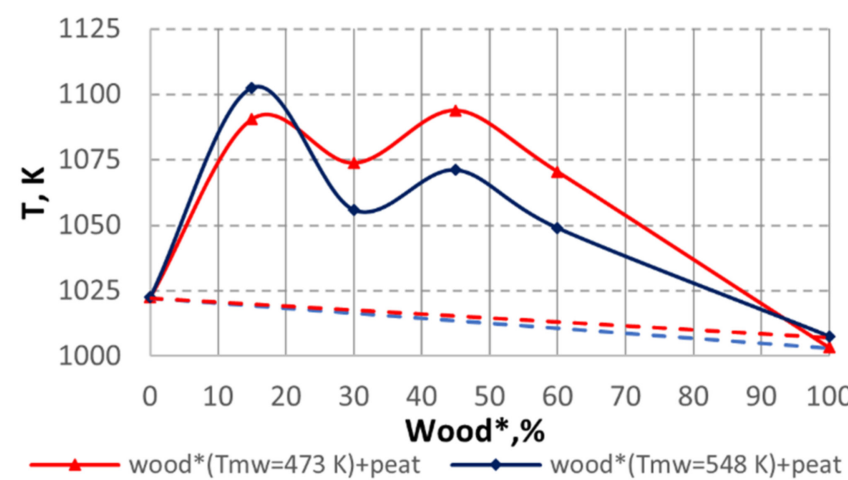

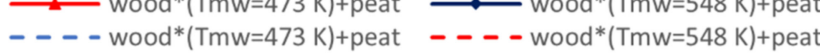

(b)

Figure 4. Effect of changes (variations) in pre-treatment temperature and composition of selectively pre-treated wheat $\operatorname{straw}^{*}(\mathbf{a})$ and $\operatorname{wood}^{*}(\mathbf{b})$ blends with raw peat pellets on the average values of the flame temperature. 
A kinetic study of the heat output from the device has further confirmed the synergetic interaction between the blend components which promoted the faster rise of the produced heat. The average value of the produced heat was observed to increase up to a maximum value, when the mass fraction of pre-treated pellets in the blends approached $45-60 \%$ (Figure $5 a, b)$. Besides, increasing the mass fraction of pre-treated pellets in the blend correlates with the increase of the produced heat energy during thermo-chemical conversion of pre-treated pellets. This confirms that the pre-treatment of wheat straw and wood pellets completes the combustion of biomass blends with a positive effect of MW pre-treatment on heat energy production. For the blends of pre-treated wheat straw and wood pellets with peat, the produced heat energy at a peak value of the heat output can be increased from $11.2 \mathrm{MJ} / \mathrm{kg}$ during thermo-chemical conversion of raw peat to about $12-13 \mathrm{MJ} / \mathrm{kg}$. A higher increase of the produced heat energy by about 11.6-16.8\% was observed for the blends of raw peat with pre-treated wood pellets when the mass fraction of wood pellets in the blend reaches $45-60 \%$.

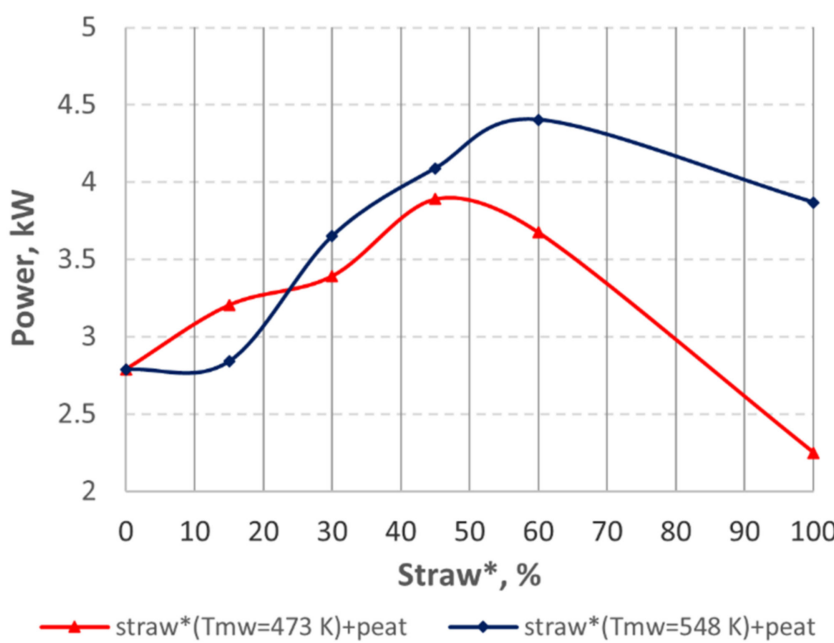

(a)

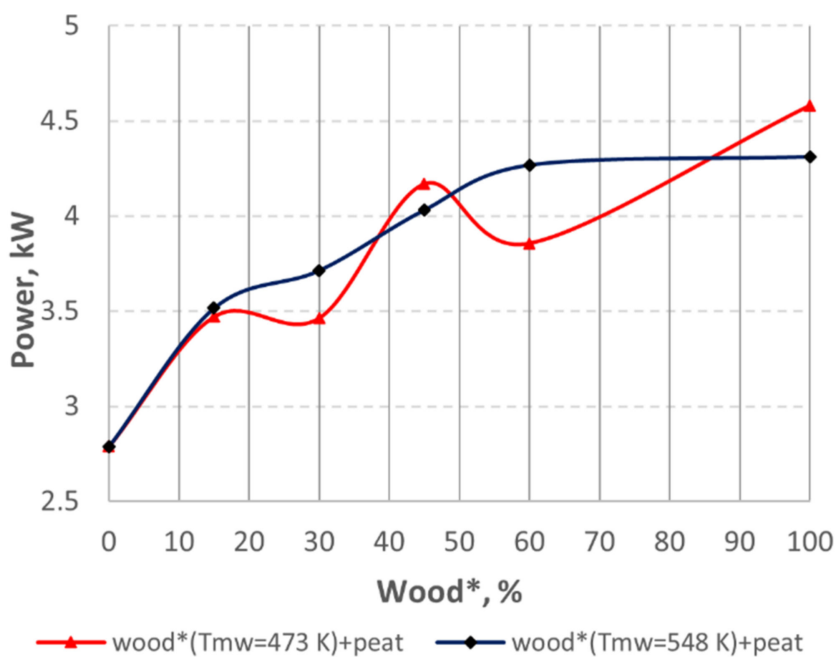

(b)

Figure 5. Effect of changes (variations) in pre-treatment temperature and composition of selectively pre-treated wheat straw* (a) and $\operatorname{wood}^{*}(\mathbf{b})$ blends with raw peat pellets on the average values of heat power.

For all selectively activated biomass blends of MW pre-treated wood or wheat straw pellets with raw peat, the addition of pre-treated pellets increased the heat energy produced per mass of the burned blend. A higher increase of the produced heat energy was observed with the addition of pre-treated wood $(\approx 12.5 \%)$ and wheat straw pellets $(\approx 15 \%)$ to the blends with raw peat when the mass fraction of pre-treated pellets in the blend reaches $30 \%-45 \%$ and the temperature of MW pre-treatment approached $523 \mathrm{~K}$.

\subsection{Effect of Selective MW Pre-Treatment of Blends on the Composition of Emissions}

The synergetic interactions between the components during thermo-chemical conversion of biomass blends also show the positive effects on the formation of emissions and on the combustion efficiency, confirming the faster formation of $\mathrm{CO}_{2}$ emissions along with the faster increase of combustion efficiency and decrease of polluting $\mathrm{NO}_{\mathrm{x}}$ emissions in the products. Increasing the mass fraction of pre-treated wheat straw pellets in the blends to about $45-60 \%$ and the temperature of MW pre-treatment of pellets to about $548 \mathrm{~K}$ correlates with the increase of the average values of $\mathrm{CO}_{2}$ up to peak values and combustion efficiency during thermo-chemical conversion of the blends (Figure 6a,c). This increase in efficiency corresponds to an increase of the produced heat energy per mass of the burned mixture by about $15 \%$ relative to the data on the specific heat emission of the raw components of the blend. 


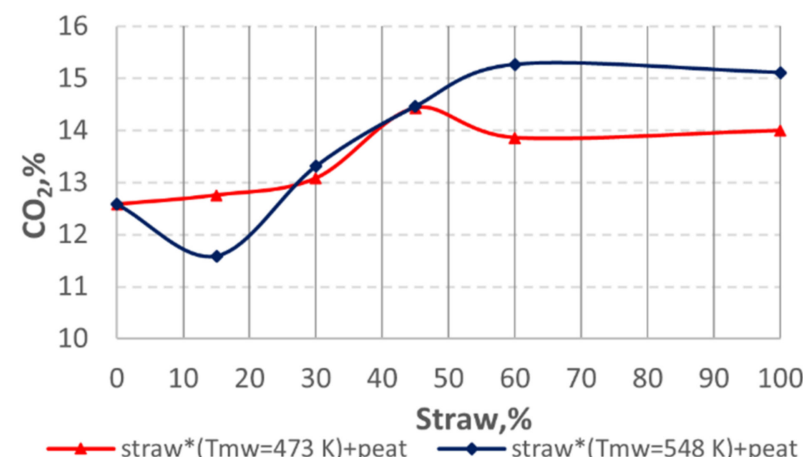

(a)

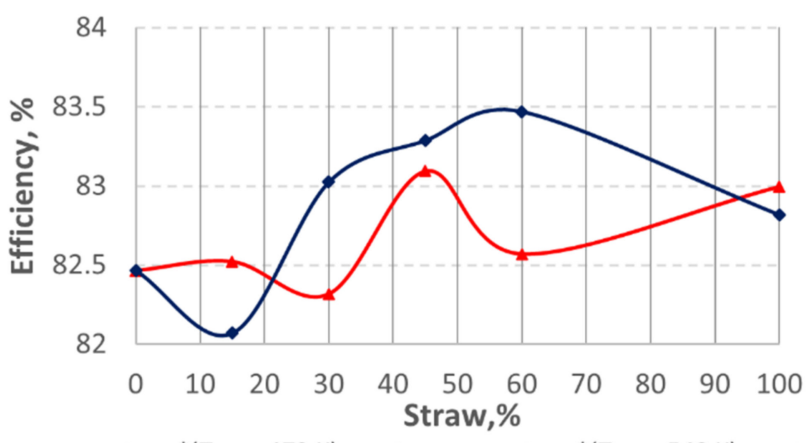

(c)

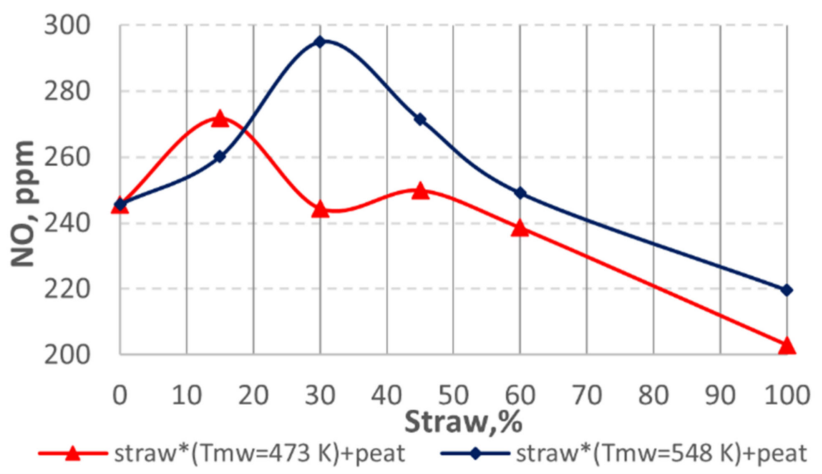

(e)

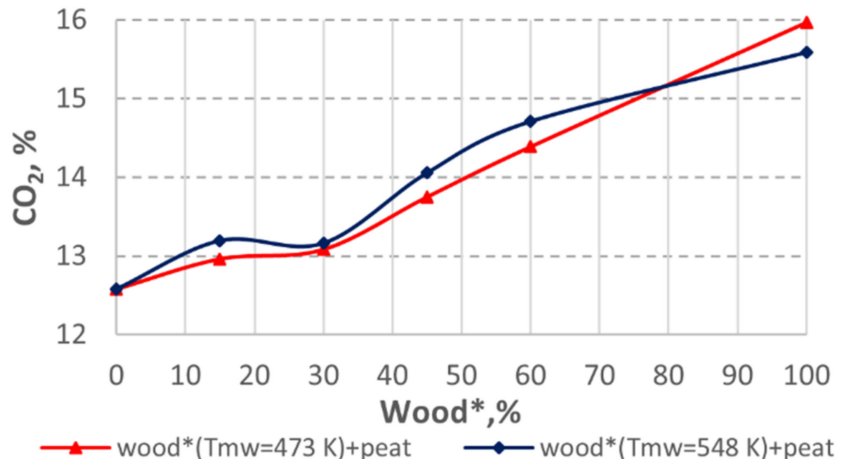

(b)

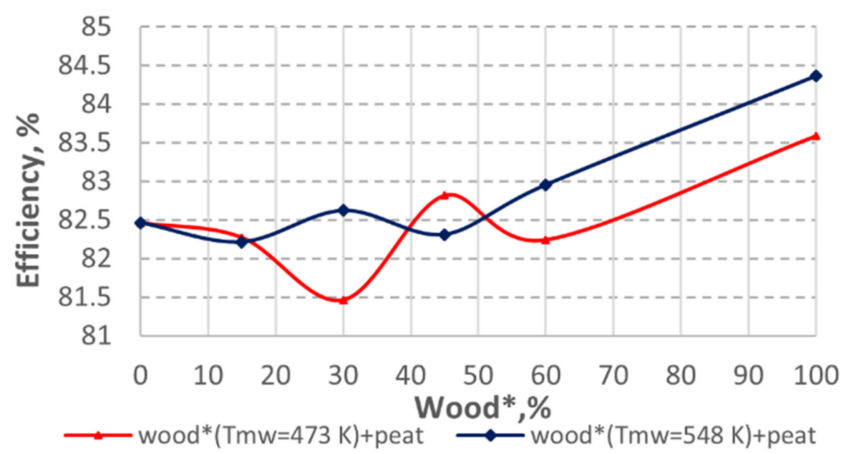

(d)

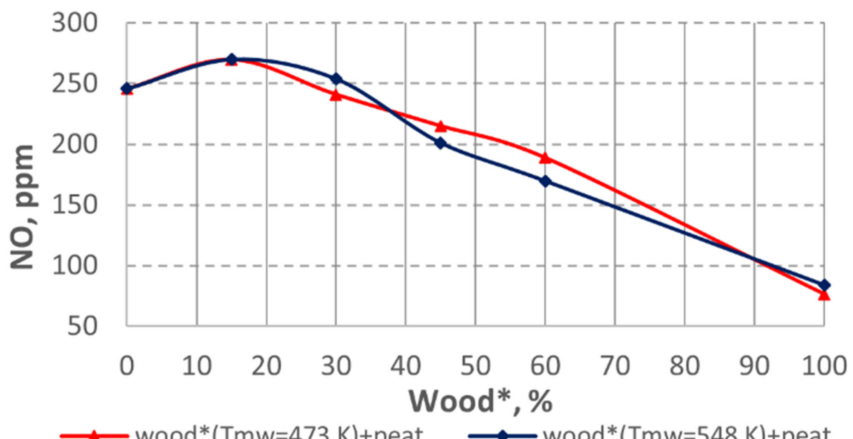

(f)

Figure 6. Effect of changes (variations) in pre-treatment temperature and composition of selectively pre-treated wheat straw* $(\mathbf{a}, \mathbf{c}, \mathbf{e})$ and $\operatorname{wood}^{*}(\mathbf{b}, \mathbf{d}, \mathbf{f})$ blends with raw peat pellets on the average values of the volume fraction of $\mathrm{CO}_{2}$ emission in the products $(\mathbf{a}, \mathbf{b})$, combustion efficiency $(\mathbf{c}, \mathbf{d})$ and on the mass fraction of $\mathrm{NO}_{\mathrm{x}}$ emission in the products $(\mathbf{e}, \mathbf{f})$.

The mass fraction of $\mathrm{NO}_{\mathrm{x}}$ emissions in the blends of wheat straw with peat tends to increase to maximum values (Figure 6e). The maximum values here depend on the mass fraction of pre-treated wheat straw in the blend and on the pre-treatment temperature. The maximum value of $\mathrm{NO}_{x}$ in the products corresponds to the minimum value of the yield of $\mathrm{CO}$ emissions at the gasifier outlet. We observed a decrease in $\mathrm{NO}_{\mathrm{x}}$ emissions, which, in turn, leads to an increase in the yield of $\mathrm{CO}$ emissions (Figures 2a and 6e), as the blends of pre-treated wood pellets efficiency (Figure 6b,d) can be related to an increase of the yield of combustible volatiles at the outlet of the gasifier (Figure $2 b$ ). This is associated with more complete thermo-chemical conversion of blends, whereas the decrease of the mass fraction of $\mathrm{NO}_{\mathrm{x}}$ in the products (Figure 6f) and of the produced heat energy dominates. In the near-stoichiometric combustion conditions, the decrease of $\mathrm{NO}_{\mathrm{x}}$ emissions in the 
products can be determined by air staging [36] during thermal conversion of combustible volatiles downstream the flame.

\subsection{Numerical Model of Thermo-Chemical Conversion of Pre-Treated Straw Biomass Pellets}

\subsubsection{Numerical Model Geometry and Parameters}

Based on the results of experimental studies which show that MW pre-treatment of both straw and wood pellets at air staging activates the thermal decomposition of biomass blends (Figure 1), the work on the development of a novel numerical model started with the evaluation of the effect of MW pre-treatment on the thermal decomposition of straw pellets. A steady state model of thermo-chemical conversion of raw and pre-treated straw has been developed using the COMSOL Multiphysics commercial software. The fully coupled numerical problem was solved using the segregated PARADISO solver and pseudo time stepping technique for stabilization and acceleration up to residuals of 0.001 .

In Figure 7a,b, the geometry of the model setup used in study is shown. It consists of an 848-mm-long cylinder of $44 \mathrm{~mm}$ in radius. The active layer of biomass is placed at the bottom of the system and is $15 \mathrm{~mm}$ long. Temperature was measured at c.a. $300 \mathrm{~mm}$ from the surface of biomass. The primary air flow was supplied from the bottom similar to the experiment and the mean flowrate was $Q_{1}=40 \mathrm{~L} / \mathrm{min}$. The secondary air with the flowrate $Q_{2}=60 \mathrm{~L} / \mathrm{min}$ was supplied through a narrow gap in the wall above the biomass layer. The swirling flow was driven (initiated) by setting the azimuthal velocity component at the boundary $u_{\varphi}=1.44 \mathrm{~m} / \mathrm{s}$. The outflow of gases occurred at the top of the cylinder. At the radial boundaries, axial symmetry and water-cooled wall boundary conditions were considered.

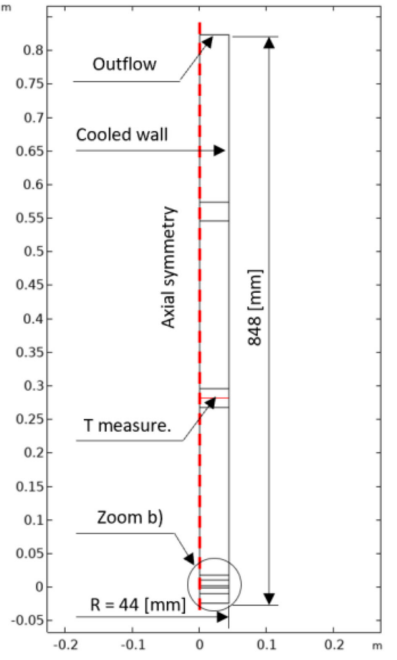

(a)

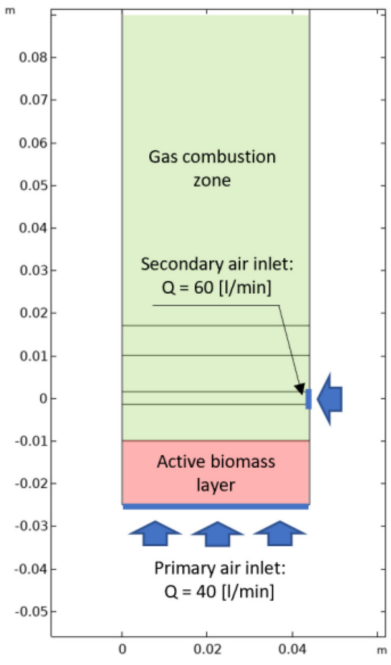

(b)

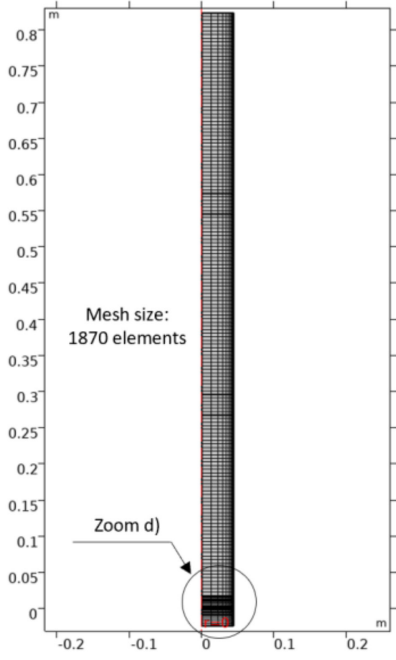

(c)

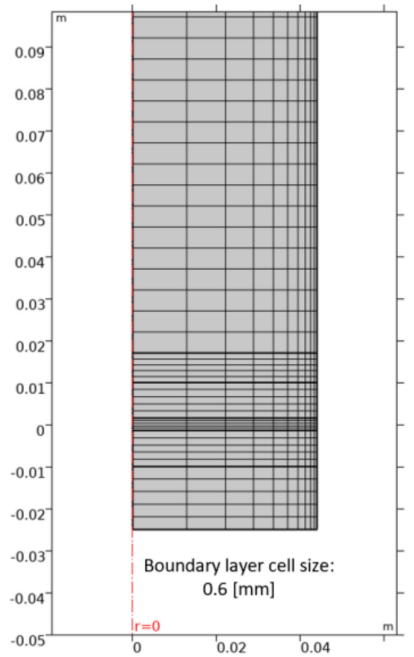

(d)

Figure 7. Model geometry (a,b) and mesh (c) used in numerical study (d).

The mesh on the model consisted of 1870 quadrilateral elements and is illustrated in detail in Figure $7 \mathrm{c}, \mathrm{d}$. The characteristic cell size at the boundary was $0.6 \mathrm{~mm}$.

To set up the model, two separated processes must be considered: the thermal decomposition of biomass and the combustion of decomposed products. Both processes and the considered assumptions are discussed in detail below.

\subsubsection{Modelling MW Pre-Treatment Effect on Thermal Decomposition of Straw Biomass Pellets}

The presented experimental results show that MW pre-treated biomass pellets (straw, wood) can be used to enhance the thermo-chemical conversion of selectively activated biomass blends, which can be related to the effect of MW pre-treatment on the enhanced 
thermal decomposition of pellets. In a recent study, to provide modelling of thermal decomposition of selectively activated biomass blends, effects of the changes (variations) of the MW pre-treatment regime on the thermal decomposition of straw pellets were considered using the experimental data of proximate analysis [34] and of the weight loss of wheat straw pellets which are summarized in Table 1.

Table 1. Proximate analysis of straw biomass pellets and estimated steady state mass loss rate.

\begin{tabular}{cccccc}
\hline $\mathbf{T}_{\mathbf{m w}}, \mathbf{K}$ & Moist. $\%$ & Ash, $\%$ & Vol, $\%$ & Char, $\%$ & $\mathbf{d m} / \mathbf{d t}, \mathbf{g} / \mathbf{s}$ \\
\hline- & 10 & 5 & 75.9 & 24.1 & 0.3 \\
\hline 473 & 2 & 5 & 72.2 & 27.8 & 0.39 \\
\hline 523 & 2 & 7.5 & 64.3 & 35.7 & 0.38 \\
\hline 548 & 2 & $8.75^{1}$ & $49.15^{1}$ & $50.85^{1}$ & 0.37 \\
\hline 573 & 2 & 13.75 & 34 & 66 & 0.42 \\
\hline
\end{tabular}

${ }^{1}$ Interpolated data.

The experiments showed that after additional heat supply to the top layer of pellets to initiate thermal decomposition of straw pellets, the temperature above the biomass layer (c.a. $15 \mathrm{~mm}$ ) rapidly grew from 373 to at least $1150 \mathrm{~K}$. In that relatively thin biomass layer, the thermal decomposition of wheat straw pellets occurred and a large amount of heat was released due to char combustion. Proper modelling of both processes in this layer is of highest importance in the model.

A modified model of wheat straw thermal decomposition (biomass particle pyrolysis) [24] is used which considers primary and secondary reactions:

$$
[\text { Biomass }] \rightarrow\left[k_{\text {vol }} \cdot \text { Volatiles }\right]_{1}+\left[k_{\text {char }} \cdot \text { Char }\right]_{1}+\Delta H_{1} \rightarrow[\text { Gas }]_{2}+[\text { Char }]_{2}+\Delta H_{2}
$$

where primary reactions are related to the thermal decomposition of biomass in volatiles (tar and gas) and in char, but secondary reactions refer to the further decomposition of volatiles and to the chemical interactions between the components that lead to the final composition of the components. $k_{v o l}$ and $k_{\text {char }}$ are the mass fractions of volatiles and char summarized in Table 1. The heat of primary exothermic reactions is $\Delta H_{1}=-255 \mathrm{~kJ} / \mathrm{kg}$ and that of secondary endothermic reactions is $\Delta H_{2}=20 \frac{\mathrm{kJ}}{\mathrm{kg}}$ [37]. This leads to the following production rates of the volatile and char components:

$$
\begin{aligned}
R_{\text {vol }} & =\frac{k_{v o l}}{V} \frac{d m}{d t}\left(1-w_{\text {moist }}-w_{\text {ash }}\right) \\
R_{\text {char }} & =\frac{k_{\text {char }}}{V} \frac{d m}{d t}\left(1-w_{\text {moist }}-w_{\text {ash }}\right)
\end{aligned}
$$

The released heat from primary and secondary reactions is calculated as:

$$
Q_{\text {pyr }}=-\left(R_{\text {vol }}+R_{\text {char }}\right)\left(\Delta H_{1}+\Delta H_{2}\right)
$$

It is assumed that the primary reactions related to the release of volatiles consist of tar and gas components [38]:

$$
\left[k_{\text {vol }} \cdot \text { Volatiles }\right]_{1}=\left[k_{t a r} \cdot \text { Tar }+k_{g a s} \cdot G a s\right]_{1}
$$

where $k_{t a r}=71.65 \%$ and $k_{g a s}=28.35 \%$ are the mass fraction coefficients [38]. Thus, the production rates of gas and tar are:

$$
\begin{aligned}
& R_{\text {gas }}=k_{\text {gas }} R_{v o l} \\
& R_{\text {tar }}=k_{\text {tar }} R_{v o l}
\end{aligned}
$$


The composition of gas can be further expanded. In this study, methane and higher hydrocarbons were neglected and their mass fraction contributed to CO:

$$
\left[k_{\text {gas }} \cdot \mathrm{Gas}\right]_{1}=\left[k_{\mathrm{CO}_{2}-\mathrm{gas}} \cdot \mathrm{CO}_{2}+k_{\mathrm{CO}-\mathrm{gas}} \cdot \mathrm{CO}+k_{\mathrm{H}_{2}-\mathrm{gas}} \cdot \mathrm{H}_{2}\right]_{1}
$$

where $k_{\mathrm{CO}_{2}-\text { gas }}=63 \%, k_{\mathrm{CO}-\text { gas }}=35.8 \%$ and $k_{\mathrm{H}_{2}-\text { gas }}=1.2 \%$ are the mass fraction coefficients, leading to the following production rates of species [38]:

$$
\begin{aligned}
R_{\mathrm{CO}_{2}-\text { gas }} & =k_{\mathrm{CO}_{2}-\text { gas }} R_{\text {gas }} \\
R_{\mathrm{CO}-\text { gas }} & =k_{\mathrm{CO}-\text { gas }} R_{\text {gas }} \\
R_{\mathrm{H}_{2}-\text { gas }} & =k_{\mathrm{H}_{2}-\text { gas }} R_{\text {gas }}
\end{aligned}
$$

In secondary reactions, mainly the oxidation of tar is considered [38] in the endothermic process. Tar is modelled as hydrocarbon $\mathrm{CH}_{1.84} \mathrm{O}_{0.96}$ that is fully decomposed into $\mathrm{CO}$ and $\mathrm{H}_{2} \mathrm{O}$ during gasification:

$$
\mathrm{CH}_{1.84} \mathrm{O}_{0.96}+0.48 \mathrm{O}_{2} \rightarrow \mathrm{CO}+0.92 \mathrm{H}_{2} \mathrm{O}+\Delta \mathrm{H}_{2}
$$

This leads to the following production rates of species from tar oxidation:

$$
\begin{gathered}
R_{C O-t a r}=\frac{M_{C O}}{M_{t a r}} \cdot R_{t a r} \\
R_{\mathrm{H}_{2} \mathrm{O}-\mathrm{tar}}=0.92 \frac{M_{\mathrm{H} 2 \mathrm{O}}}{M_{t a r}} \cdot R_{t a r} \\
R_{\mathrm{O}_{2}-\text { tar }}=-0.48 \frac{M_{\mathrm{O}_{2}}}{M_{t a r}} \cdot R_{t a r}
\end{gathered}
$$

\subsubsection{Char Oxidation}

In this study, char oxidation is modelled implicitly using the measured char amount converted to gases $\mathrm{CO}$ and $\mathrm{CO}_{2}$ and heat. It is considered that char oxidation occurs in the top biomass layer and is described by the reaction [39]:

$$
\mathrm{C}+\frac{1}{\theta} \mathrm{O}_{2} \rightarrow 2\left(1-\frac{1}{\theta}\right) \mathrm{CO}+\left(\frac{2}{\theta}-1\right) \mathrm{CO}_{2}+\Delta \mathrm{H}
$$

where $\theta$ is a parameter of the stoichiometric oxygen amount $\mathrm{CO} / \mathrm{CO}_{2}$ and of the ratio of generation [40]:

$$
\begin{gathered}
\theta=\frac{1+\mathrm{CO} / \mathrm{CO}_{2}}{1+0.5 \mathrm{CO} / \mathrm{CO}_{2}} \\
\frac{\mathrm{CO}}{\mathrm{CO}_{2}}=12 \exp \left(-\frac{3300}{\mathrm{~T}}\right)
\end{gathered}
$$

Thus, the total heat of the reaction can be calculated as:

$$
\Delta H=2\left(1-\frac{1}{\theta}\right) \Delta H_{C O}+\left(\frac{2}{\theta}-1\right) \Delta H_{C_{2}}
$$

where $\Delta H_{C O}=-123.1 \frac{\mathrm{kJ}}{\mathrm{mol}}$ and $\Delta H_{\mathrm{CO}_{2}}=-393.5 \frac{\mathrm{kJ}}{\mathrm{mol}}$.

The production and consumption rates in the active layer of biomass are:

$$
\begin{aligned}
& R_{\mathrm{CO}-\text { char }}=2\left(1-\frac{1}{\theta}\right) \cdot \frac{M_{\mathrm{CO}}}{M_{c}} \cdot R_{\text {char }} \\
& R_{\mathrm{CO}_{2}-\text { char }}=\left(\frac{2}{\theta}-1\right) \cdot \frac{M_{\mathrm{CO}_{2}}}{M_{\mathrm{c}}} \cdot R_{\text {char }}
\end{aligned}
$$




$$
R_{\mathrm{O}_{2}-\text { char }}=-\frac{1}{\theta} \cdot \frac{M_{\mathrm{O}_{2}}}{M_{\mathcal{C}}} \cdot R_{\text {char }} .
$$

This shows the total amount of heat generated in the active layer due to the combustion of char:

$$
Q_{\text {char }}=-\left(\Delta H_{\mathrm{CO}} R_{\mathrm{CO}-\text { char }}+\Delta \mathrm{H}_{\mathrm{CO}_{2}} R_{\mathrm{CO}_{2}-\text { char }}\right) .
$$

\subsubsection{Release of Moisture}

The production rate of water from moisture is:

$$
R_{\text {H2O-moist }}=\frac{1}{V} \frac{d m}{d t} w_{\text {moist }} .
$$

The release of water requires an additional heat that can be calculated as:

$$
Q_{\mathrm{H}_{2} \mathrm{O}}=-\left(C_{p-H 2 \mathrm{O}} \Delta T+\Delta H_{\text {evap }}\right) R_{H 2 \mathrm{O}-\text { moist }}
$$

where $C_{p-H 2 O}=4200 \frac{\mathrm{kJ}}{\mathrm{kg} \cdot \mathrm{K}}$ is the heat capacity of water, $\Delta T=80 \mathrm{~K}$ is the temperature difference, and $\Delta H_{\text {evap }}=2260 \mathrm{~kJ}$ is the latent heat of water evaporation.

\subsubsection{Combustion of Gases}

Upon considering the pyrolysis and char oxidation processes, the combustion of $\mathrm{CO}$ and $\mathrm{H}_{2}$ outside the active layer of biomass was studied. Reactions (3) and (5) were considered.

In this study, sufficiently high Reynolds and Damköhler numbers were considered; therefore, the flow was assumed turbulent and the reaction rate $r_{i} \frac{1}{m^{3} s \cdot m o l}$ was determined by the characteristics of turbulent mixing and by an eddy dissipation model instead of the mean-value-closure rate [41].

The heat generated from the reactions is calculated as:

$$
Q_{i}=r_{i} \Delta H_{i}
$$

\subsubsection{System of Equations for Gas Mixture Modelling}

The transport of species is modelled using the steady state convection diffusion reaction equation:

$$
\rho(\boldsymbol{u} \nabla) \omega_{i}=-\nabla \boldsymbol{j}_{\boldsymbol{i}}+R_{i}
$$

where $\omega_{i}$ is the mass fraction of species, $j_{i} \frac{\mathrm{kg}}{\mathrm{m}^{2} \mathrm{~s}}$ stands for the mass flux relative to the average velocity, $R_{i} \frac{\mathrm{kg}}{\mathrm{m}^{3} \mathrm{~s}}$ is the production rate of species, $u, \frac{\mathrm{m}}{\mathrm{s}}$ denotes the velocity field, and $\rho \frac{\mathrm{kg}}{\mathrm{m}^{3}}$ is the mean density of the mixture.

In the active layer of biomass, the production rate of species is:

$$
\begin{gathered}
R_{\mathrm{CO}}=R_{\mathrm{CO}-\text { gas }}+R_{\mathrm{CO}-\text { tar }}+R_{\mathrm{CO}-\text { char }} \\
R_{\mathrm{CO}_{2}}=R_{\mathrm{CO}_{2}-\text { gas }}+R_{\mathrm{CO}_{2}-\text { char }} \\
R_{\mathrm{H}_{2}}=R_{\mathrm{H}_{2}-\text { gas }} \\
R_{\mathrm{H}_{2} \mathrm{O}}=R_{\mathrm{H}_{2} \mathrm{O}-\text { tar }}+R_{\mathrm{H}_{2} \mathrm{O}-\text { moist }} \\
R_{\mathrm{O}_{2}}=R_{\mathrm{O}_{2}-\text { tar }}+R_{\mathrm{O}_{2}-\text { char }}
\end{gathered}
$$

The sum of mass fractions of all species is:

$$
\sum_{i=1}^{n} \omega_{i}=1
$$


A non-isothermal, 2D-axisymetric swirling mixture flow was modelled using RANS equations, the standard k- $\omega$ turbulence model, and considering gravity forces along with the continuity equation:

$$
\begin{gathered}
\rho(\boldsymbol{u} \nabla) \boldsymbol{u}=\nabla(-p+K)+\rho \boldsymbol{g}+\boldsymbol{F} \\
\nabla(\rho \boldsymbol{u})=0
\end{gathered}
$$

where $p, P a$ denotes pressure, $K, P a$ is the shear and Reynolds stress tensor, $g, \frac{m}{s^{2}}$ is the gravitational acceleration, $\boldsymbol{F}, \frac{\mathrm{N}}{\mathrm{m}^{3}}$ denotes external forces.

Boundary conditions of constant velocity air inflow are imposed at the primary and secondary flow inlets, the zero-pressure boundary condition is set at the outlet of the system, and wall functions are applied to the walls of the reactor vessel.

An additional volume force modelling the flow through porous media is applied to the layer of biomass:

$$
\boldsymbol{F}=-\frac{\mu}{k_{c}} \boldsymbol{u}
$$

where $\mu=10^{-5} \mathrm{~Pa} \cdot \mathrm{s}$ is the dynamic viscosity of the mixture, $k_{c}=10^{-6} \mathrm{~m}^{-2}$ is the permeability of the biomass pellet bed which can be estimated from the Carman-Kozeny equation [42].

Heat transfer is modelled considering the work done by the pressure variation:

$$
\rho C_{p}(\boldsymbol{u} \nabla) T=k_{m i x} \Delta T-\left.\frac{T}{\rho} \frac{\partial \rho}{\partial T}\right|_{p} \cdot(\boldsymbol{u} \nabla) p+Q_{i}+Q_{p y r}+Q_{c h a r}+Q_{H 2 O}
$$

where $C_{p} \frac{\mathrm{J}}{\mathrm{kg} \cdot \mathrm{K}}$ is the heat capacity of the gas mixture, and $k_{m i x}=0.1 \frac{\mathrm{W}}{\mathrm{m} \cdot \mathrm{K}}$ is the thermal conductivity of the gas mixture.

In the active layer of biomass, additional heat source terms $Q_{p y r}, Q_{c h a r}$, and $Q_{H 2 O}$ are introduced from the processes of pyrolysis, char combustion, and moisture evaporation.

The constant temperature boundary condition $273 \mathrm{~K}$ is applied at the primary and secondary flow inlets. The insulating boundary condition is imposed at the outlet and a convective cooling boundary condition is applied on other radial walls.

\subsubsection{Results of Numerical Modelling}

A parametric study of a different source material according to Table 1 has been carried out, and typical distributions of the fields are shown in Figures 8-11 for the thermal decomposition and combustion of raw straw.

In Figure 8a, a temperature distribution is shown. It can be seen that a maximum temperature is achieved in the upper part of the flame reaching c.a. $1600 \mathrm{~K}$. This distribution changed noticeably after MW pre-treatment when torrefaction of pellets became more important, more heat was released in the active biomass layer. and the temperature maximum shifted downwards, as shown in Figure 9a. It should be noted that both the flame width and the height were larger for pre-treated pellets.

By analysing the velocity distribution in both cases Figures $8 b$ and $9 b$, a similar velocity distribution was obtained. A strong swirling flow was observed up to 400-mm height. The recirculation of the secondary air had a significant effect only close to the biomass layer and its effects rapidly decreased with the height. The highest axial velocity is observed on the axis. 


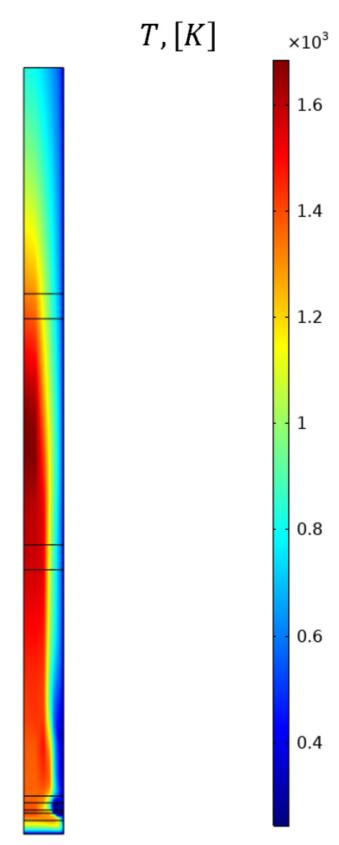

(a)

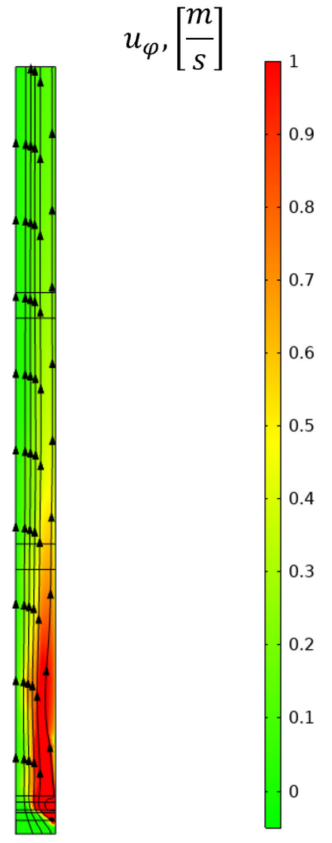

(b)

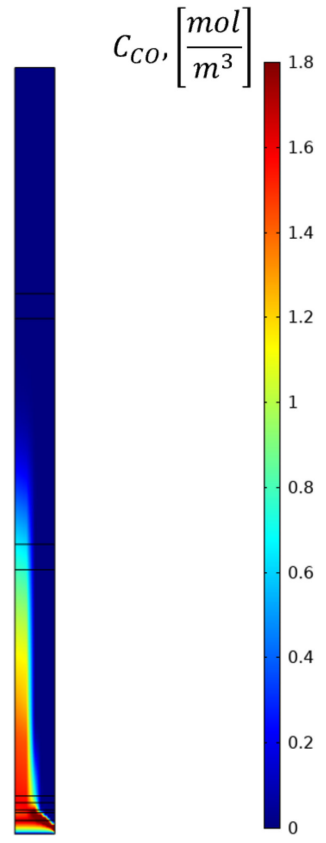

(c)

Figure 8. Distributions of fields when using raw straw pellets: (a) temperature, (b) velocity, (c) concentration of $\mathrm{CO}$.

$T,[K]$

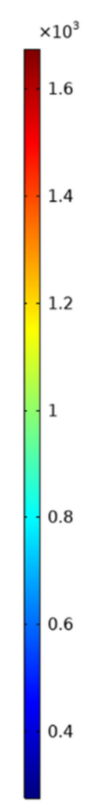

(a)

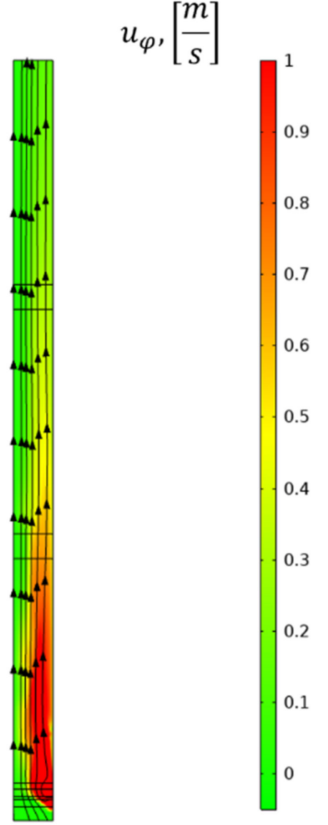

(b)

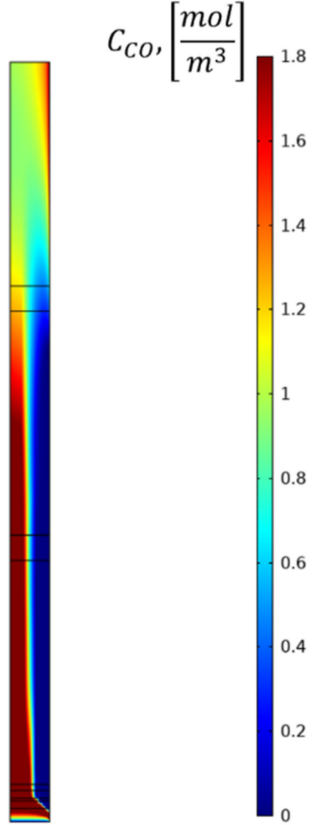

(c)

Figure 9. Distributions of fields when using MW pre-treated straw pellets: $\mathrm{T}_{\mathrm{MW}}=473 \mathrm{~K}$ : (a) temperature, (b) velocity field, (c) concentration of CO. 


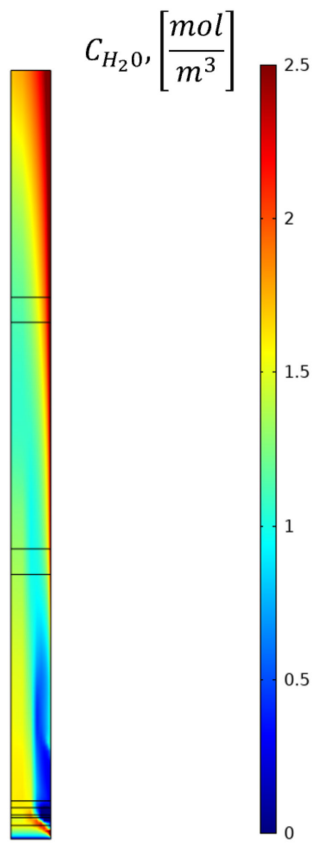

(a)

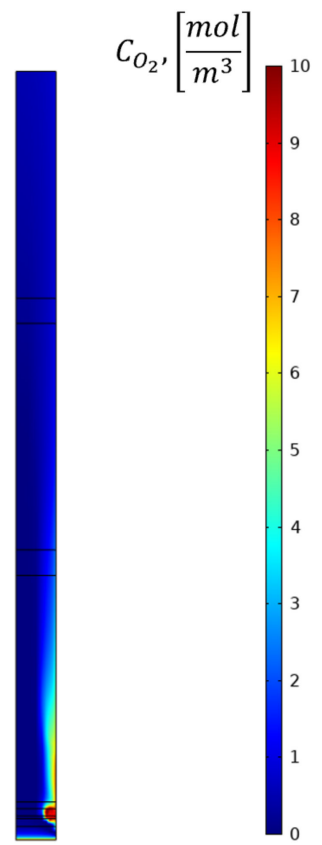

(b)

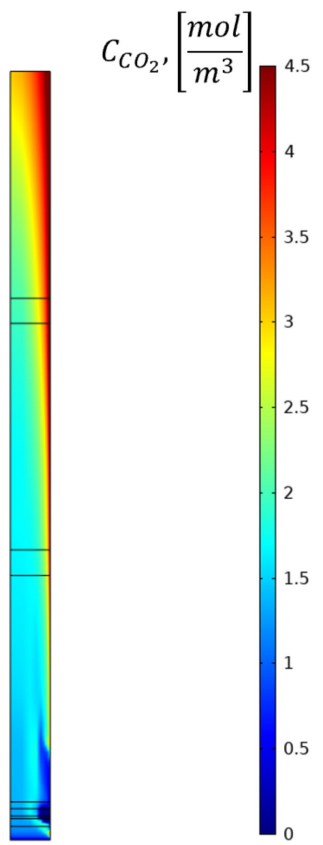

(c)

Figure 10. Distributions of fields when using raw straw pellets: concentration of $(\mathbf{a}) \mathrm{H}_{2} \mathrm{O},(\mathbf{b}) \mathrm{O}_{2}$, (c) $\mathrm{CO}_{2}$.

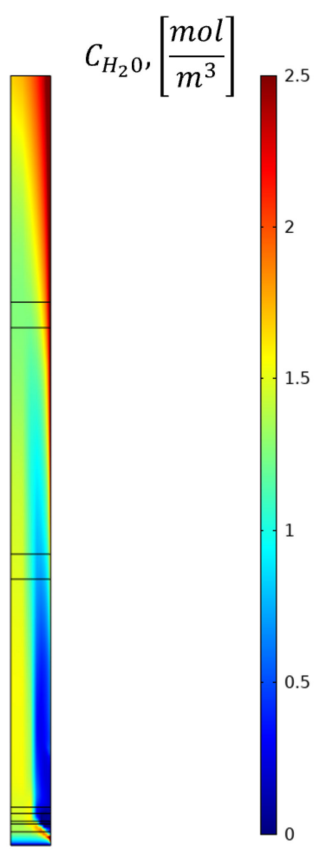

(a)

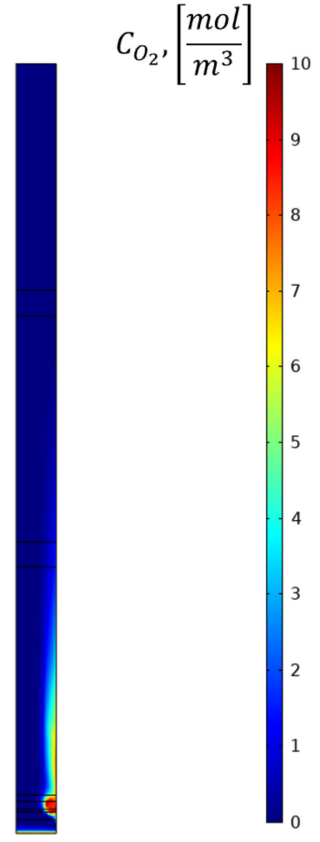

(b)

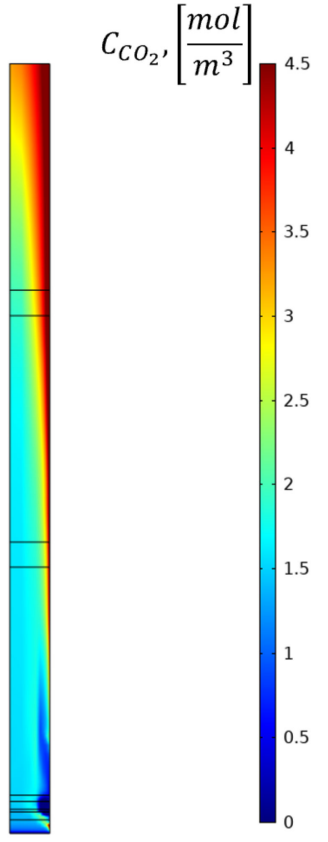

(c)

Figure 11. Distribution of fields when using MW pre-treated straw pellets $\mathrm{T}_{\mathrm{MW}}=473 \mathrm{~K}$ : concentration of (a) $\mathrm{H}_{2} \mathrm{O}$, (b) $\mathrm{O}_{2}$, (c) $\mathrm{CO}_{2}$.

A significantly higher concentration of $\mathrm{CO}$ was found for pre-treated pellets (Figure 9c) compared to raw pellets (Figure 8c). Such an effect was directly connected to the higher temperature in the biomass layer, partly due to the much lower moisture content. Since the 
temperature determines the $\mathrm{CO} / \mathrm{CO}_{2}$ generation ratio during char combustion, with the increased temperature only partial combustion of char occurred and more $\mathrm{CO}$ was generated.

The distributions of $\mathrm{H}_{2}, \mathrm{O}_{2}$ and $\mathrm{CO}_{2}$ concentrations are compared in Figures 10 and 11. Although not identical, the overall distribution of these species was similar in both presented (considered, discussed) cases.

In Table 2, the total generated heat, the mean temperature in the measurement area, and the mass fraction of all modelled species are compared for different straw pellet pre-treatment conditions.

Table 2. Calculated combustion output parameters of straw pellets with different treatment conditions.

\begin{tabular}{ccccccccc}
\hline \multirow{2}{*}{$\mathbf{T}_{\mathbf{M W}}, \mathbf{K}$} & $\mathbf{Q}, \mathbf{k W}$ & $\mathbf{T}, \mathbf{K}$ & \multicolumn{5}{c}{ Mass Fraction at Outlet: } \\
\cline { 4 - 9 } & & & $\mathbf{C O}$ & $\mathbf{C O}_{\mathbf{2}}$ & $\mathbf{H}_{\mathbf{2}}$ & $\mathbf{O}_{\mathbf{2}}$ & $\mathbf{N}_{\mathbf{2}}$ & $\mathbf{H}_{\mathbf{2}} \mathbf{O}$ \\
\hline- & 3.77 & 1042 & $0.0 \%$ & $30.1 \%$ & $0.0 \%$ & $3.4 \%$ & $59.6 \%$ & $7.0 \%$ \\
\hline 473 & 4.50 & 1153 & $6.1 \%$ & $33.1 \%$ & $0.0 \%$ & $1.6 \%$ & $52.2 \%$ & $7.0 \%$ \\
\hline 523 & 4.55 & 1155 & $6.8 \%$ & $33.0 \%$ & $0.0 \%$ & $2.4 \%$ & $51.9 \%$ & $5.9 \%$ \\
\hline 548 & 4.79 & 1184 & $9.2 \%$ & $33.5 \%$ & $0.0 \%$ & $4.9 \%$ & $48.0 \%$ & $4.4 \%$ \\
\hline 573 & 5.32 & 1225 & $14.3 \%$ & $35.3 \%$ & $0.0 \%$ & $9.6 \%$ & $37.4 \%$ & $3.4 \%$ \\
\hline
\end{tabular}

It can be deduced that using MW pre-treatment of straw pellets predicts a significant increase of the generated power by $0.73 \mathrm{~kW}$ at an MW pre-treatment temperature of $473 \mathrm{~K}$ and by up to $1.55 \mathrm{~kW}$ with the MW pre-treatment temperature increase to $573 \mathrm{~K}$. The predicted averaged flame temperature also increased by more than $100 \mathrm{~K}$ under the $473 \mathrm{~K}$ MW pre-treatment temperature regime and by $182 \mathrm{~K}$ under the $573 \mathrm{~K} \mathrm{MW}$ pre-treatment regime. This suggests that the pre-treated biomass pellets act as a source to enhance the thermo-chemical conversion of selectively activated biomass blends, as it follows from the results of the experimental study with similar effects of MW pre-treatment of straw and wood pellets on the kinetics of the weight loss rates and on the temperature of the flame reaction zone at the thermo-chemical conversion of selectively activated biomass blends.

By analysing the mass fraction of species in the reactor output, it was found that the amount of non-reacted $\mathrm{CO}$ increased with increasing pre-treatment temperature of the fuel, whereas the oxygen content initially decreased, but increased afterwards. This suggests that the model predicts incomplete combustion of $\mathrm{CO}$ that could be caused either by the shortage of oxygen or by the insufficient mixing intensity/length in the system. An acceptable combustion of reactants was obtained only with raw straw pellets.

\section{Conclusions}

The presented results of MW pre-treatment of biomass pellets show that improvement of the main characteristics, i.e., increased heating value and reactivity of wood or straw pellets, was achieved. This makes possible partial replacement of raw peat pellets with pre-treated wood or straw pellets, producing, in this way, selectively activated biomass blends with improved combustion characteristics, which provides a wider use of available regional biomass feedstock for heat production. The following precise conclusions can be made.

First, MW pre-treatment of pellets caused a synergetic interaction between the intermediate products of thermal conversion of the blends components, which promoted their thermal decomposition and the release of combustible volatiles.

The enhanced yield of combustible volatiles correlated with the decrease of the air excess ratio during the gasification of the fuel blends, which limited the thermo-chemical conversion of volatiles during the gasification of biomass blends, which, in turn, restrained the increase of the heat release and the synergetic effect on the weight loss rates related to the thermal interaction of components, as the mass fraction of pre-treated pellets in the blend increased above $45 \%$ and the temperature of MW pre-treatment increased to $548 \mathrm{~K}$. 
The synergetic effect of the thermal interaction between the components influenced the kinetics of the flame reaction zone formation, providing a faster rise of the temperature and heat power, increasing their average values to the maximum, which corresponded to the mass fraction of pre-treated pellets in the blend about $45 \%$. Besides, an increase of the produced heat energy per mass of the burned blends by $15 \%$ confirmed the improved combustion of selectively activated blends.

The improvement of the combustion of selectively activated blends was also confirmed by the increase of carbon-neutral $\mathrm{CO}_{2}$ emissions in the products and by the combustion efficiency. A decrease of the average values of $\mathrm{NO}_{x}$ emissions in the products was observed, which indicated a cleaner and more efficient thermo-chemical conversion of selectively activated biomass blends and can stimulate a wider use of regional heat energy resources for cleaner and efficient energy production.

The experimental results confirm that the thermo-chemical conversion of blends of peat with selectively microwave-activated wood or wheat straw pellets can be used to control the combustion characteristics of lignocellulosic biomass and, therefore, utilize more completely its energetic potential as of a renewable solid fuel.

The developed novel 2D numerical model of thermal decomposition and combustion of straw biomass pellets has shown that main effects, such as the increase of released heat, the generation of combustible volatiles, can be also predicted numerically (Table 2) and qualitatively agree with the obtained experimental results. The obtained results show that the temperature distribution in the case of MW pre-treated pellets varies significantly, mainly due to the higher release of $\mathrm{CO}$ in the active layer of biomass, which can be caused by the insufficient supply of air in the numerical model. The presented model describing the effect of MW pre-treatment on straw pellets is one of a kind, and work on the further development of the numerical model will be continued.

Author Contributions: Conceptualization, M.Z. and A.A.; data curation, L.G. and R.V.; formal analysis, M.Z. and A.A.; funding acquisition, M.Z.; investigation, L.G., R.V. and M.G.D.; methodology, R.V., M.Z. and A.A.; project administration, M.Z.; resources, R.V. and M.Z.; supervision: M.Z. and A.A.; visualization: M.Z., A.A. and L.G.; writing-original draft, M.Z., A.A. and L.G.; writingreview and editing, M.Z., L.G., M.G.D. and A.A. All authors have read and agreed to the published version of the manuscript.

Funding: This research was funded by the European Regional Development Fund under Grant No. 1.1.1.1/19/A/010

Institutional Review Board Statement: Not applicable.

Informed Consent Statement: Not applicable.

Data Availability Statement: The data presented in this study are available on request from the corresponding author.

Conflicts of Interest: The authors declare no conflict of interest.

\section{Nomenclature}

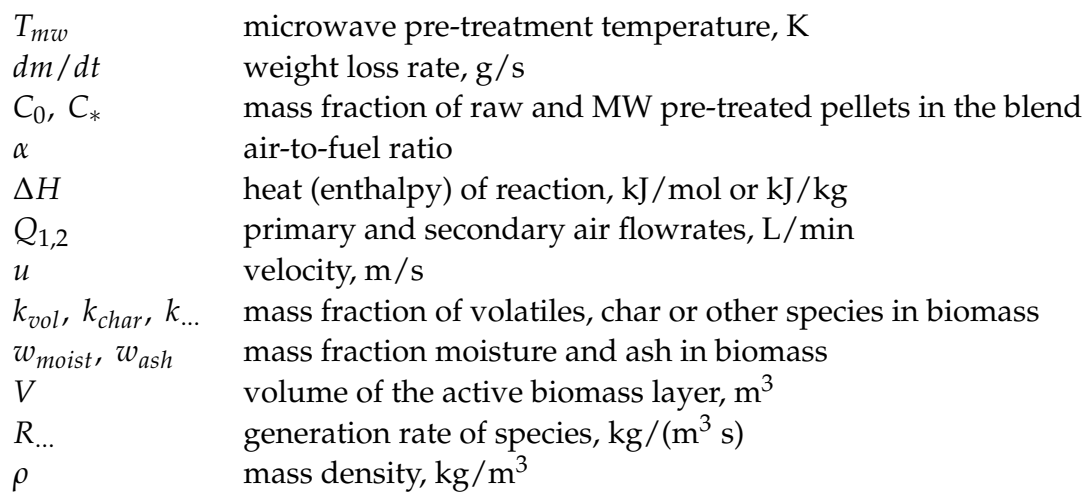




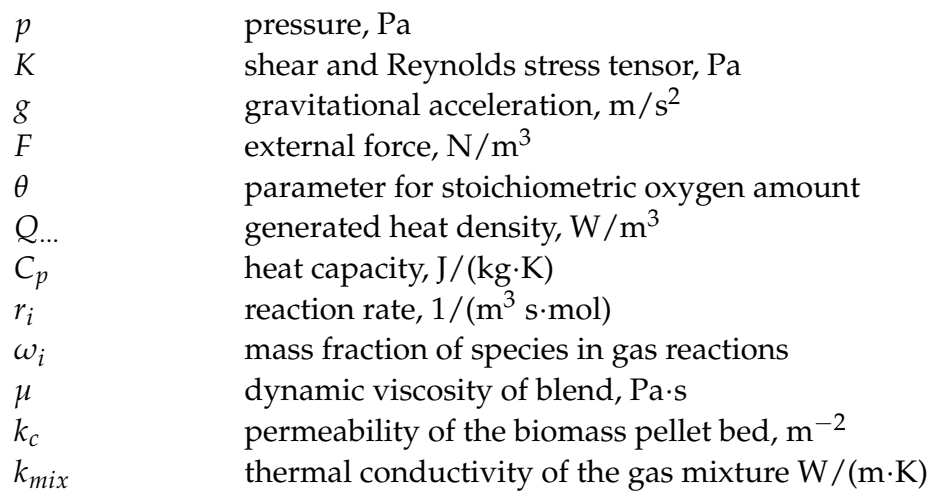

\section{References}

1. EU Climate Action and the European Green Deal. 2030 Climate Target Plan I Climate Action (europa.eu). Available online: https:/ / ec.europa.eu/clima/eu-action/european-green-deal/2030-climate-target-plan_en (accessed on 16 January 2022).

2. Bui, H.-H.; Tran, K.-Q.; Chen, W.-H. Pyrolysis of microalgae residues-A Kinetic study. Bioresour. Technol. 2015, 199, 362-366. [CrossRef] [PubMed]

3. $\quad$ Chen, W.H.; Lin, B.J.; Lin, Y.Y.; Chu, Y.S.; Ubando, A.T.; Show, P.L.; Ongh, H.C.; Chang, J.S.; Ho, S.H.; Culaba, A.B.; et al. Progress in biomass torrefaction: Principles, applications and challenges. Prog. Energy Combust. Sci. 2021, 82, 10087. [CrossRef]

4. Vassilev, S.; Baxter, D.; Andersen, L.K.; Vassileva, C.G. An overview of the chemical composition of biomass. Fuel 2010, 89, 913-933. [CrossRef]

5. Mocraoui, S. Introduction to Biomass Energy Conversion. 2015. Available online: https://set.ksu.edu.sa/sites/set.ksu.edu.sa/ files/imce_images/third_series_by_dr-_salim.pdf (accessed on 16 January 2022).

6. Van der Stelt, M.J.C. Chemistry and Reaction Kinetics of Biowaste Torrefaction. Ph.D. Thesis, Eindhoven University of Technology, Eindhoven, The Netherlands, 2011; p. 245. [CrossRef]

7. Mamvura, T.A.; Danha, G. Biomass torrefaction as an emerging technology to aid in energy production. Heliyon 2020, 6, 503-531. [CrossRef]

8. Chen, W.H.; Peng, J.; Bi, X.T. A state of the art review of biomass torrefaction, densification and applications. Renew. Sustain. Energy Rev. 2015, 44, 847-866. [CrossRef]

9. Basu, P.; Sadhukhan, A.K.; Gupta, P.; Rao, S.; Dhungana, A.; Acharya, B. An experimental and theoretical investigation on torrefaction of a large wet wood particle. Bioresour. Technol. 2014, 159, 215-222. [CrossRef]

10. Barskov, S.; Zappi, M.; Buchireddy, P.; Dufreche, S.; Guillory, J.; Gang, D.; Hernandez, R.; Bajpai, R.; Baudier, J.; Cooper, R.; et al. Torrefaction of biomass: A review of production methods for biocoal from cultured and waste lignocellulosic feedstocks. Renew. Energy 2019, 142, 624-642. [CrossRef]

11. Technology Status and Commercialisation, Applications for Torrefied Biomass and Its Role in Logistics and Trade Webinar. Available online: www.ieabioenergy.com (accessed on 16 January 2022).

12. Plans for New Bio-Coal Plant in Estonia, HD Forest. 2018. Available online: https://www.hdforest.com/news/plans-for-newbio-coal-plant-in-estonia (accessed on 16 January 2022).

13. Thrän, D.; Witt, J.; Schaubach, K.; Kiel, J.; Carbo, M.; Maier, J.; Ndibe, C.; Koppejan, J.; Alakangas, E.; Majer, S.; et al. Moving torrefaction towards market introduction. Technical improvements and economic-environmental assessment along the overall torrefaction supply chain through the SECTOR project. Biomass Bioenergy 2016, 89, 184-200. [CrossRef]

14. Huang, Y.-F.; Chiueh, P.-T.; Kuan, W.-H.; Lo, S.-L. Effects of lignocellulosic composition and microwave poer level on the gaseous product of microwave pyrolysis. Energy 2015, 89, 974-981. [CrossRef]

15. Huang, Y.-F.; Chiueh, P.-T.; Lo, S.-L. A review on microwave pyrolysis of lignocellulosic biomass. Sustain. Environ. Res. 2016, 26, 103-109. [CrossRef]

16. Kostas, E.T.; Beneroso, D.; Robinson, J.P. The application of microwave heating in bioenergy: A review on the microwave pre-treatment and upgrading technologies for biomass. Renew. Sustain. Energy Rev. 2017, 77, 12-27. [CrossRef]

17. Arshanitsa, A.; Akishin, Y.; Zile, E.; Dizhbite, T.; Solodovnik, V.; Telysheva, G. Microwave treatment combined with conventional heating of plant biomass pellets in a rotated reactor as a high rate process for solid biofuel manufacture. Renew. Energy 2016, 91, 386-396. [CrossRef]

18. Andersone, A.; Arshanitsa, A.; Akishin, Y.; Semenischev, A.; Telysheva, G. Microwave assisted torrefaction of plant biomass of different origin with focus on the solid products valorisation for energy and byond. Chem. Eng. Trans. 2021, 86, 109-114.

19. Arshanitsa, A.; Dizhbite, T.; Bikovens, O.; Pavlovich, G.; Andersone, A.; Telysheva, G. Effects of Microwave Treatment on the Chemical Structure of Lignocarbohydrate Matrix of Softwood and Hardwood. Energy Fuels 2016, 30, 457-464. [CrossRef]

20. Lauberts, M.; Lauberte, L.; Arshanitsa, A.; Dizhbite, T.; Dobele, G.; Bikovens, O.; Telysheva, G. Structural transformations of wood and cereal biomass components induced by microwave assisted torrefaction with emphasis on extractable value chemicals obtaining. J. Anal. Appl. Pyrolysis 2018, 134, 1-11. [CrossRef]

21. Hupa, M. Interaction of fuels in co-firing in FBC. Fuel 2005, 84, 1312-1319. [CrossRef] 
22. Quan, C.; Gao, N. Co-pyrolysis of coal: A review of effects of co-pyrolysis parameters, products properties, and synergistic mechanisms. Appl. Biotechnol. Prod. Biomass Based Fuels 2016, 2016, 6197867. [CrossRef]

23. Oladejo, J.; Shi, K.; Meng, Y.; Adegbite, S.; Wu, T. Biomass constituents' interactions with coal during co-firing. Energy Procedia 2019, 158, 1640-1645. [CrossRef]

24. Xue, J.; Ceylan, S.; Goldfarb, L. Synergism among biomass building blocks? Evolved gas and kinetics analysis of starch and cellulose pyrolysis. Thermochim. Acta 2015, 618, 36-47. [CrossRef]

25. Wu, Z.; Wang, S.; Zhao, J.; Meng, H. Synergistic effect on thermal behavior during co-pyrolysis of lignocellulosic biomass model components blend with bituminous coal. Bioresour. Technol. 2014, 169, 220-228. [CrossRef]

26. Vuppaladadiyam, A.K.; Antunes, E.; Sanchez, P.B.; Duan, H.; Zhao, M. Influence of microalgae on synergism during co-pyrolysis with organic waste biomass: A thermogravimetric and kinetic analysis. Renew. Energy 2021, 167, 42-55. [CrossRef]

27. Oyedun, O.; Gebreegziabher, T.; Hui, C.-W. Co-pyrolysis of biomass and plastics waste. Chem. Eng. Trans. 2013, 35, 883-888.

28. Lanigan, B. Microwave Processing of Lignocellulosic Biomass for Production of Fuels. Ph.D. Thesis, University of York, New York, NY, USA, 2010.

29. Goldšteins, L.; Valdmanis, R.; Zake, M.; Arshanitsa, A.; Andersone, A. Thermal Decomposition and Combustion of Microwave Pre-Treated Biomass Pellets. Processes 2021, 9, 429. [CrossRef]

30. Goldsteins, L.; Valdmanis, R.; Zake, M. Activated combustion of biomass blends by microwave pre-treatment of straw. Eng. Rural Dev. 2021, 20, 152-156. [CrossRef]

31. Barmina, I.; Goldsteins, L.; Valdmanis, R.; Zake, M. Improvement of biomass gasification/combustion characteristics using the microwave pre-treatment of biomass pellets. Combust. Eng. Technol. 2021, 44, 2018-2025. [CrossRef]

32. Larina, O.M.; Sinelshchikov, V.A.; Sytchev, G.A. Comparison of thermal conversion methods of different biomass types into gaseous fuel. J. Phys. Conf. Ser. 2016, 774, 1-7. [CrossRef]

33. Fatehi, H. Numerical Simulation of Combustion and Gasification of Biomass Particles. Ph.D. Thesis, Division of Fluid Mechanics, Department of Energy Sciences Faculty of Engineering LTH, Lund University, Lund, Sweden, 2014; p. 90.

34. Arshanitsa, A.; Andersone, A.; Telysheva, G. Non-isothermal thermal analysis of different originated lignocellulosic biomass, non-treated and torrified by microwave treatment. Eng. Rural Dev. 2021, 20, 424-430.

35. Yang, H.; Yan, R.; Chen, H.; Lee, D.H.; Zheng, C. Characteristics of hemicellulose, cellulose and lignin pyrolysis. Fuel 2007, 86, 1781-1788. [CrossRef]

36. Haushfar, E.; Levas, T.; Skreiberg, O. Experimental investigation on NOx reduction by primary measures in biomass combustion: Straw, peat, sewage sludge, forest residues and wood pellets. Energies 2012, 5, 270-290. [CrossRef]

37. Koufopanos, C.A.; Papayannakos, N.; Maschio, G.; Lucchesi, A. Modelling of the Pyrolysis of Biomass Particles. Studies on Kinetics, Thermal and Heat Transfer Effects. Can. J. Chem. Eng. 1991, 69, 907-915. [CrossRef]

38. Zhou, H.; Jensen, A.D.; Glarborg, P.; Jensen, P.A.; Kavaliauskas, A. Numerical modelling of straw combustion in a fixed bed. Fuel 2005, 84, 389-403. [CrossRef]

39. Miltner, M.; Makaruk, A.; Harasek, M.; Friedl, A. Computational fluid dynamic simulation of a solid biomass combustor: Modelling approaches. Clean Technol. Environ. Policy 2008, 10, 165-174. [CrossRef]

40. Pedersen, K. The Product Ratio of $\mathrm{CO} / \mathrm{CO}_{2}$ in the Oxidation of Biomass Char. Master's Thesis, Technical University of Denmark, Lyngby, Denmark, 2003.

41. Magnussen, B.F.; Hjertager, B.H. On mathematical modelling of turbulent combustion with special emphasis on soot formation and combustion. Symp. Combust. 1977, 16, 719-729. [CrossRef]

42. Richardson, J.F.; Harker, J.H.; Backhurst, J.R. CHAPTER 4-Flow of fluids through granular beds and packed columns. In Chemical Engineering, 5th ed.; Richardson, J.F., Harker, J.H., Backhurst, J.R., Eds.; Butterworth-Heinemann: Oxford, UK, 2002; Volume 2, pp. 191-236. 